\title{
$\delta$-Tocotrienol feeding modulates gene expression of EIF2, mTOR, protein ubiquitination through multiple-signaling pathways in chronic hepatitis $C$ patients
}

Asaf A. Qureshi ${ }^{1 *}$, Dilshad A. Khan², Shahida Mushtaq ${ }^{2}$, Shui Qing Ye ${ }^{1,3,4}$, Min Xiong ${ }^{1,3}$ and Nilofer Qureshi ${ }^{1,5}$

\begin{abstract}
Background: $\delta$-Tocotrienol is a naturally occurring proteasome inhibitor, which has the capacity to inhibit proliferation and induce apoptosis in several cancer cells obtained from several organs of humans, and other cancer cell lines. Moreover, results of plasma total mRNAs after $\delta$-tocotrienol feeding to hepatitis $C$ patients revealed significant inhibition in the expression of pro-inflammatory cytokines (TNF-a, VCAM1, proteasome subunits) and induction in the expression of ICAM1 and IFN- $\gamma$ after post-treatment. This down-regulation of proteasome subunits leads to autophagy, apoptosis of immune cells and several genes. The present study describes RNA-sequence analysis of plasma total mRNAs obtained from $\delta$-tocotrienol treatment of hepatitis $C$ patients on gene expression regulated by proteasome.
\end{abstract}

Methods: Pooled specimens of plasma total mRNAs of pre-dose versus post-dose of $\delta$-tocotrienol treatment of hepatitis C patients were submitted to RNA-sequence analyses. The data based on $>1$ and 8-fold expression changes of 2136 genes were uploaded into "Ingenuity Pathway Analyses (IPA)" for core analysis, which describes possible canonical pathways, upstream regulators, diseases and functional metabolic networks.

Results: The IPA of "molecules" indicated fold change in gene expression of 953 molecules, which covered several categories of biological biomarkers. Out of these, gene expression of 220 related to present study, 12 were up-regulated, and 208 down-regulated after $\delta$-tocotrienol treatment. The gene expression of transcription regulators (ceramide synthase 3 and Mohawk homeobox) were up-regulated, and gene expression of 208 molecules were down-regulated, involved in several biological functions (HSP90AB1, PSMC3, CYB5R4, NDUFB1, CYP2R1, TNFRF1B, VEGFA, GPR65, PIAS1, SFPQ, GPS2, EIF3F, GTPBP8, EIF4A1, HSPA14, TLR8, TUSSC2). IPA of "causal network" indicated gene regulators (676), in which 76 downregulated (26s proteasomes, interleukin cytokines, and PPAR-ligand-PPA-Retinoic acid-RXRa, PPARY-ligand-PPARY-Retinoic acid-RARa, IL-21, IL-23) with significant $P$-values. The IPA of "diseases and functions" regulators (85) were involved with CAMP, STAT2, 265 proteasome, CSF1, IFNy, LDL, TGFA, and microRNA-155-5p, miR-223, miR-21-5p. The IPA of "upstream analysis" (934) showed 57 up-regulated (mainly 38 microRNAs) and 64 gene regulators were down-regulated (IL-2, IL-5, IL6, IL-12, IL-13, IL-15, IL-17, IL-18, IL-21, IL-24, IL-27, IL-32), interferon $\beta-1$ a, interferon $\gamma$, TNF-a, STAT2, NOX1, prostaglandin J2, NF-KB, 1KB, TCF3, and also miRNA-15, miRNA-124, miRNA-218-5P with significant activation of Z-Score $(P<0.05)$.

Conclusions: This is first report describing RNA-sequence analysis of $\delta$-tocotrienol treated plasma total mRNAs obtained from chronic hepatitis C patients, that acts via multiple-signaling pathways without any side-effects. These studies may lead to development of novel classes of drugs for treatment of chronic hepatitis $C$ patients.

Keywords: $\delta$-Tocotrienol, Chronic hepatitis C, RNA-sequence, Gene expression of biomarkers, Causal network, Diseases and functions, Up-stream regulators, Canonical pathways

\footnotetext{
*Correspondence: qureshia@umkc.edu

'Department of Biomedical Science, School of Medicine, University of

Missouri-Kansas City, 2411 Holmes Street, Kansas City, MO 64108, USA

Full list of author information is available at the end of the article
}

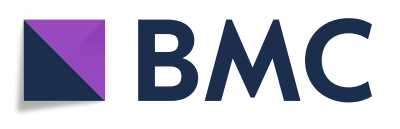

(c) The Author(s). 2018 Open Access This article is distributed under the terms of the Creative Commons Attribution 4.0 International License (http://creativecommons.org/licenses/by/4.0/), which permits unrestricted use, distribution, and

reproduction in any medium, provided you give appropriate credit to the original author(s) and the source, provide a link to the Creative Commons license, and indicate if changes were made. The Creative Commons Public Domain Dedication waiver (http://creativecommons.org/publicdomain/zero/1.0/) applies to the data made available in this article, unless otherwise stated. 


\section{Background}

We have recently reported that $\delta$-tocotrienol is a potent anti-cancer agent (liver, pancreas, prostrate, breast cancer cell lines, Hela, melanoma, B lymphocytes and T-cells), and also a modulator of proteasome function, as compared to other outstanding proteasome inhibitors (thiostrepton, 2-methoxyestradiol, and quercetin) [1]. Moreover, plasma total mRNAs obtained from $\delta$-tocotrienol treated hepatitis $C$ patients showed significant inhibition in the expression of pro-inflammatory cytokines (TNF- $\alpha$ and VCAM-1), and induction in expression of ICAM-1, IFN- $\gamma$, whereas proteasome subunits $\mathrm{X}, \mathrm{Y}, \mathrm{Z}, \mathrm{LMP}$, LMP2, LMP10 (22-44\%) were significantly inhibited compared to pre-dose values, and this down-regulation of proteasome subunits leads to autophagy and apoptosis of cells [1]. The present study is an extension of these findings to study the effect of $\delta$-tocotrienol (Fig. 1) treatment of chronic hepatitis $C$ patients in their plasma mRNAs using RNA-Sequencing by Ingenuity Pathway Analysis (IPA). The viral infection with hepatitis $\mathrm{C}$ is responsible for a vast majority of chronic hepatitis cases over 180 million people worldwide, which is further supported by epidemiological and clinical studies have also demonstrated a causative role of viral infection of hepatitis $C$ in the development of hepatocellular carcinoma [2]. These figures are alarming, as patients currently asymptomatic with relatively mild disease may eventually progress to complications of chronic liver diseases, like cirrhosis, and hepatocellular carcinoma [3]. The mechanisms of liver disease are not fully understood.

The mechanisms that contribute to the pathogenesis of hepatitis virus-related liver infections are diverse and very complex. Investigation of altered cellular mechanisms through gene profiling techniques has improved the clear understanding of various disease processes and development of novel therapeutic targets [4]. Earlier, techniques applied for studying gene expression profiling included microarrays, which analyzes quantitative expression of thousands of genes, and time consuming real-time PCR assays that gives only small number of expression of genes. These tools have been used previously for identification of differentially expressed genes in hepatitis $\mathrm{C}$ virus associated cirrhosis and carcinoma [5]. In summary, these changes in gene expression were associated with immune response, fibrosis, cellular growth, proliferation, and apoptosis [5-7]. Nowadays, similar estimation carried out by RNA-sequence procedure, which will provide very accurate gene expression of several virus important biological functions and biomarkers.

The genotype hepatitis $\mathrm{C}$ is an important determinant of the response to treatment, and differences found in clinical outcomes of the disease with respect to infection of various genotypes [6-8]. The genotype 3 is the most prevalent genotype around the world compared to other genotype infection [8]. In the present study we will identify altered cellular processes in chronic hepatitis $\mathrm{C}$ patients after treatment with $\delta$-tocotrienols. The main purpose of this preliminary study was to isolate plasma total mRNAs from a few participants after $\delta$-tocotrienol treatment of chronic hepatitis $C$ patients, and to carry out RNA-sequence analysis, which quantified mRNA expression of a large number of genes in pooled specimens of pre-dose versus post-dose of $\delta$-tocotrienol treatment of chronic hepatitis $\mathrm{C}$ patients. The gene expression data was analyzed by "Ingenuity Pathway Analysis", which would reveal the cellular and biological mechanisms at the molecular level in plasma total mRNAs obtained from chronic hepatitis $\mathrm{C}$ patients.

\section{Methods}

Materials

DeltaGold $125 \mathrm{mg}$ softgels from annatto seeds (typical composition $90 \% \delta$-tocotrienol and $10 \% \gamma$-tocotrienol) were supplied by American River Nutrition, Inc. (Hadley,

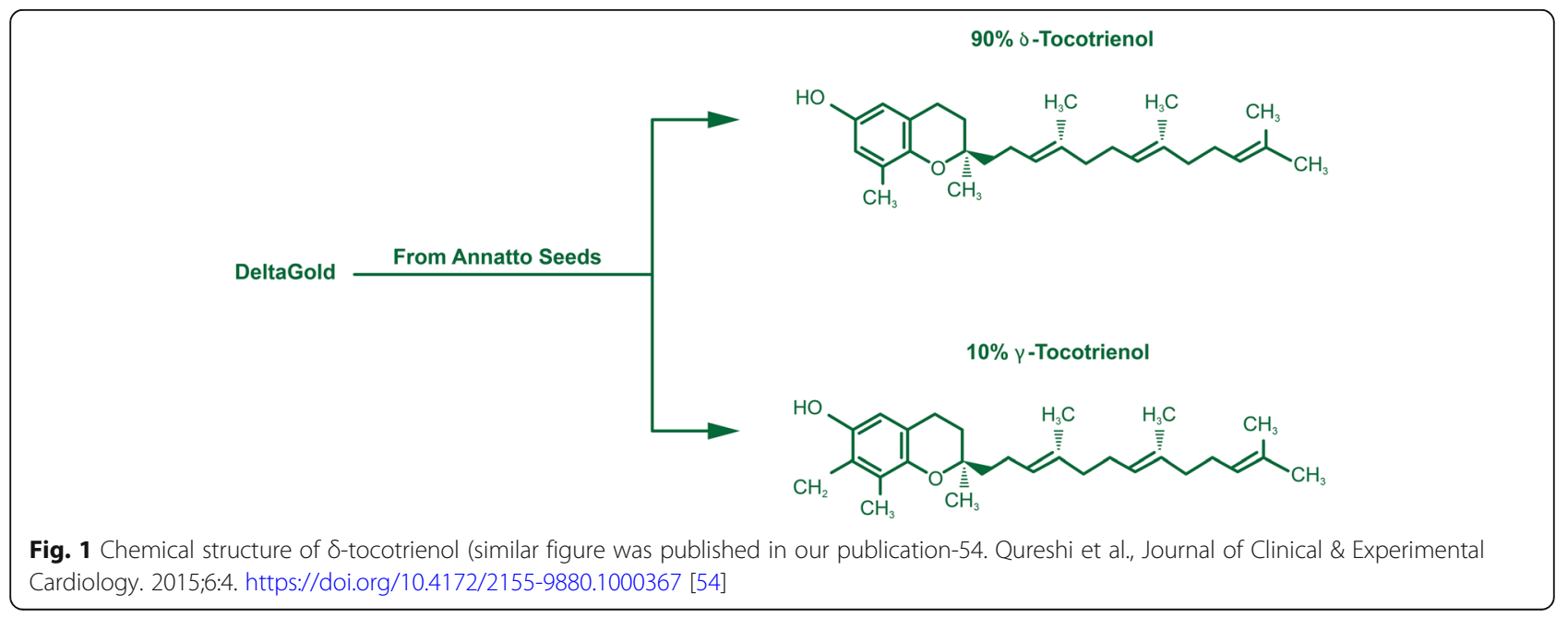


MA, USA). RNeasy mini kit was obtained from QIAGEN Sciences (Germantown, MD, USA).

Impact of $\delta$-tocotrienol in chronic hepatitis $C$ patients The study was carried out in Pakistan Ordinance Factory (POF) Hospital, Wah Cantonment, Rawalpindi, Pakistan; in collaboration with department of biomedical Sciences, University of Missouri-Kansas City, MO, USA. The study protocol was registered (IRB \# 129-2015) was approved by Institutional Review Board of POF, Rawalpindi, Pakistan. The study was carried out under a FDA approved IND number 36906. The hepatitis $C$ antibody test was purchased from Sigma Chemical Co., St. Louis, USA. The second diagnosing hepatitis $\mathrm{C}$ test is RNA PCR test was obtained from the EDTA treated fresh whole blood by using total RNA purification kit \# 17200 (NORGEN Bioteck Corporation, Thorold, ON, Canada).

\section{RNA-Sequence Analyses of plasma total RNAs obtained from EDTA treated whole blood after feeding $\delta$ - tocotrienol for 6-weeks to hepatitis $C$ patients}

The details of study design, inclusion/exclusion criteria, experimental design, and physical characteristics of hepatitis $\mathrm{C}$ patients were same as reported [1]. In short, the total mRNA was extracted from plasma of EDTA treated fresh whole blood of each hepatitis $C$ patients $(n=14)$ fed $\delta$-tocotrienol $(500 \mathrm{mg} / \mathrm{d})$ for 6 weeks by total RNA purification kit (NORGEN Bioteck Corporation, Thorold, ON, Canada). The purity of total RNAs (stored $-80^{\circ} \mathrm{C}$ ) was estimated by the ratios of $260 / 280$ (2.02-2.08) of all samples, which was determined using Thermo Scientific NanoDrop 1000 Spectrophotometer. The mRNAs samples from Pakistan were brought in person (by Dr. Dilshad A. Khan in dry ice to avoid any degradation of RNAs) to UMKC, Medical School after approval by (Compliance officer Mr. Christopher Winders, and Chemical/Biological Safety officer Mr. Mike Philips) members of University of Missouri Kansas City institutional review board.

The results of most important cytokines and other biomarkers associated with the present investigation were estimated by real-time RT-PCR by using plasma total RNAs purified from pre-dose versus post-dose samples after feeding $\delta$-tocotrienol for 6-weeks to chronic hepatitis $\mathrm{C}$ patients has been published recently [1], therefore present manuscript lacks in vitro estimations of RT-PCR data. The same plasma total RNAs were used in the present study.

The RNA-Sequence analyses were carried out at Division of Experimental and Translational Genetics, Children's Mercy Hospital, Kansas City, MO. Five randomized samples selected of total RNAs of hepatitis $\mathrm{C}$ patients, and combined. Total mRNAs of combined samples were purified by Biostic Blood Total RNA Isolation Kit (MOBIO Laboratories, Inc). The purified total mRNAs were further purified and concentrated to $10.0 \mu \mathrm{l}$ by using by Gene Jet RNA Clean up and Concentration Micro Kit (Thermo Scientific, EU, Lithuania). The purity of these RNAs was further determined in the Division of Experimental and Translational Genetic \& Core of Omic Research (The Children Mercy Hospital, Kansas City, MO) by their own instruments for quality control and quantity of each sample to make sure that each sample is up to standard before putting into a NGS run. The concentrated total mRNAs of each set was converted to cDNA, and total RNA-Seq carried out. Gene expression level and fold change (post vs pre-dose) of FPKM were calculated at $>1,>2$, or $>5$ levels at 2-fold, 4-fold, and 8-fold after filtering several million fold up-regulated and down-regulated genes (Table 1).

\section{Statistical analyses}

These data were analyzed by IPA program of treatment-mediated effects as post-dose versus pre-dose. The statistical significance level was set at $5 \%(P<0.05)$.

\section{Results}

Genome-wide profiling experiment of plasma mRNAs obtained from pre-dose and post-dose $\delta$-tocotrienol treatment of hepatitis $C$ patients

The RNA-Sequence analysis was based on FPKM >1 and 8-fold change of 2136 genes ( 0 values replaced with 0.001 ; Table 1 ) ratios of post-dose over pre-dose treatment of $\delta$-tocotrienol to hepatitis $C$ patients were uploaded into "Ingenuity Pathway Analyses (IPA)" for core analysis (Ingenuity Systems, Redwood City, CA). The various genes associated with different biological

Table 1 Estimation of basic RNA-sequence expresion unit (FPKM) of $\delta$-tocotrienol treated hepatitis $C$ patients $^{1}$

\begin{tabular}{llllll}
\hline$\#$ & RNA-Seq expression unit & Number of genes & Genes based on 2-fold & Genes based on 4-fold & Genes based on 8-fold \\
\hline 1 & FPKM $>1$ & 12614 & 9480 & 5369 & 2136 \\
2 & FPKM $>2$ & 7426 & 1366 & 696 & 527 \\
3 & FPKM $>5$ & 3323 & 379 & 285 & 268 \\
\hline
\end{tabular}

${ }^{1}$ The gene expression level and fold change (post-dose vs pre-dose) of FPKM were calculated at more than 1, 2, or 5 at 2-fold, 4-fold, and 8-fold after filtering million-fold up-regulation and down-regulation. The RNA-seq analyses data based on FPKM $>1$ and 8 -fold change of 2136 genes ( 0 values were replaced with 0.001) of ratios of post-dose over pre-dose treatment of $\delta$-tocotrienol to hepatitis C patients was submitted into "Ingenuity Pathway Analyses (IPA)" for core analysis (Ingenuity Systems, Redwood City, CA) 
functions and biomarkers are from "Ingenuity Knowledge Base" generated molecular networks, according to biological as well as molecular functions. These include canonical pathways, upstream regulatory analysis, and disease-based functional network, which helped discovering the list of several biomarkers. The core analysis was carried out with the settings of indirect and direct relationship between focused molecules based on experimentally observed data and human databases in the "Ingenuity Knowledge Base" were considered as the data sources in these analyses and pathways.

\section{"Molecules" affected by $\delta$-tocotrienol feeding to hepatitis $C$ patients}

The IPA of "molecules section" indicates fold changes in gene expression of 953 genes, which covered several categories of biological biomarkers, which are presented in the heat-map of this section (Fig. 2). Out of these, expression of 220 genes were related to present study, and only 12 genes were up-regulated (Table 2), and remaining 208 genes of various biomarkers were down-regulated after $\delta$-tocotrienol treatment (Table 3 ). The ceramide synthase 3 and Mohawk homeobox were only two up-regulated genes involved as transcription regulators. The down-regulated gene expression of 208 molecules are involved in several biological functions (Additional file 1: Table S1, Additional file 2: Table S2 and Additional file 3: Table S3). The functions of these regulators are ATPase $\mathrm{NA}^{+} / \mathrm{K}^{+}$transporting subunit $\alpha 1$, apolipoprotein $\mathrm{B}$, proteasome $26 \mathrm{~S}$ subunits, NADH ubiquinone oxidoreductase subunits B1, B9, cytochrome b5 reductase 4 , autophagy related $4 \sim 5$, cytochrome P450 family, TNF receptor superfamily $1 \mathrm{~B}, \mathrm{RAS}$ P21 protein activator 2 , ubiquitin conjugating enzyme $\mathrm{B} 2 \mathrm{~J} 1$, several other types of ubiquitin proteasome subunits, and protein inhibitor of activated STAT1 (Table 3). Similarly, gene regulator of G-protein signaling 2, nuclear factor of activated T-cells 2 interacting protein, TNF- $\alpha$ induced protein $8, \mathrm{C}-\mathrm{X}-\mathrm{C}$ motif chemokines ligand 1, RNA polymerase II subunit $\mathrm{H}$, tumor suppressor candidate 2 , splicing factor $3 \mathrm{~b}$ subunit 5 , and several miRNAs $(877,1250,140)$, RNAs, tRNAs are reported in Table 3. The summary of most important down-regulated biomarkers are HSP90AB1, IL-16, autophagy, TNFSF1B, VEGFA, NFIL3, UBP1, USP25, RASA3, USP15, UBE4A, USP19, PSMG3, IL-27RA, SCP2, IFNGR1, ID2, TUSC2, IL-1R2, IL18RP, IRF2, PCNA1250,77,40 and several tRNAs (Table 3).

\section{"Causal Networks" affected by $\delta$-tocotrienol feeding to hepatitis $C$ patients}

The down-regulation of several biomarkers of "causal network" of IPA of RNA samples obtained after treatment with $\delta$-tocotrienol of chronic hepatitis $\mathrm{C}$ patients is described in Tables 4 and 5 .

There were 676 gene regulators identified in this section, and only 98 regulators were associated with present study, indicating significant $P$-values for all regulators (Tables 4 and 5). The fold change gene expression of 24 was up-regulated (Table 4) and 74 down-regulated (Table 5). This section includes down-regulated gene expression of $26 \mathrm{~S}$ proteasomes, interleukin cytokines, and PPAR-ligand-PPA-Retinoic acid-RXT $\alpha$, PPAR $\gamma$-ligand-PPAR $\gamma$-Retinoic acid-RAR $\alpha$, IL-7R, CD80, IRS, IL-2，IL-2RG，IL-5，IL-15，IL-21,

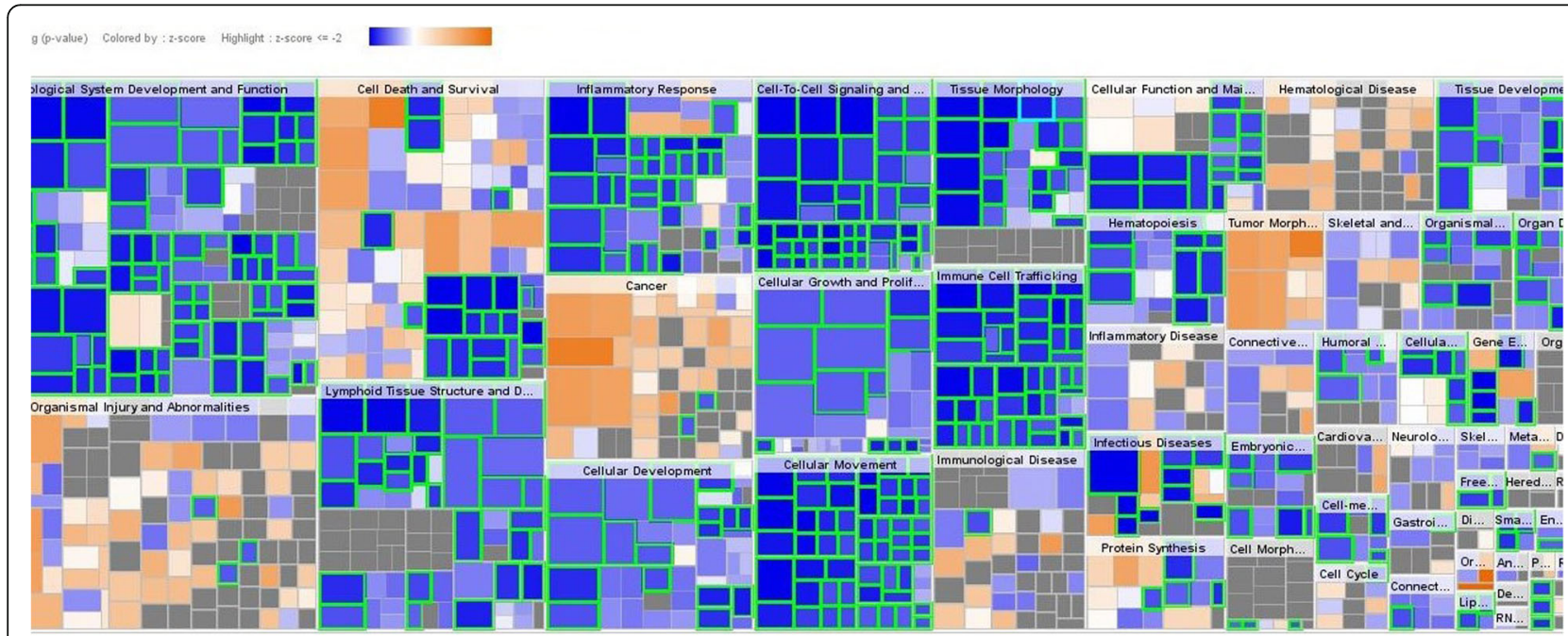

Fig. 2 Effect of several biological biomarkers in "diseases and functions" of heat map in plasma of total mRNAs obtained from $\delta$-tocotrienol treatment of hepatitis C patients. The fold change expression of several biological functions (hematological system, function development, cell death, survival, inflammatory response, cell to cell signaling, cancer, organism injury, organism abnormalities, cellular development and immunological diseases) are illustrated in heat map 
Table 2 Effect of $\delta$-tocotrienol on up-regulation of fold change gene expression of "Molecules" section (12) of IPA analysis in hepatitis $C$ patients

\begin{tabular}{lllll}
\hline Up-regulation & & & & \\
\hline$\#$ & Symbol & Entrez Gene Name & Expr Fold Change & Type(s) \\
\hline 1 & HIST1H2AD & histone cluster 1 H2A family member d & 1804955.068 & other \\
2 & HHIPL2 & HHIP like 2 & 28.710 & other \\
3 & RPP38 & ribonuclease P/MRP subunit p38 & 24.946 & enzyme \\
4 & CERS3 & ceramide synthase 3 & 19.082 & transcription regulator \\
5 & HBG1 & hemoglobin subunit gamma 1 & 17.945 & other \\
6 & MT-TQ & tRNA & 14.252 & other \\
7 & AKR1D1 & aldo-keto reductase family 1 member D1 & 14.056 & enzyme \\
8 & TSPAN15 & tetraspanin 15 & 11.523 & other \\
9 & HBG2 & hemoglobin subunit gamma 2 & 11.413 & other \\
10 & MKX & mohawk homeobox & 9.573 & transcription regulator \\
12 & P4HA3 & prolyl 4-hydroxylase subunit alpha 3 & 8.686 & enzyme \\
\hline
\end{tabular}

IL-23 and several types of microRNAs (miRNAs) as shown in Table 5. The activation Z-Score, P-values, network bias-corrected and causal network values were in descending order of all these gene biomarkers (Tables 4 and 5).

\section{"Diseases and functions" affected by $\delta$-tocotrienol feeding to hepatitis $C$ patients}

The IPA of RNAs obtained from effect of $\delta$-tocotrienol treatment of chronic hepatitis $C$ patients on relative percentage relationship of gene regulators (70) of "diseases and functions" reported in Table 6. In this section, percentage relationships of main regulators were AP1, cAMP, EIF2AK2 2RL1, IL-17A, IL-1RN, KITLG, miRNA-155-5p, STAT2 (48\%; 43/90), 26S proteasome, CSF1, IFNG, IL-17A, IRF4, LDL, RELA, TGFA (43\%; 17/40); mir-223 (0\%; $0 / 2)$, IL-15 (100\%; 1/1), IL-1B (0\%; 0/1), and miR-21-5p (100\%; 1/1) (Table 6). The consistency score of these regulators varied from $1.73 \sim 36.34$, total regulars (1-9), total node (5-57), diseases and functions total varied 1-10 as shown in Table 6.

\section{"Upstream analysis" affected by $\delta$-tocotrienol feeding to hepatitis C patients}

The most interesting results of present IPA was "upstream analysis" of $\delta$-tocotrienol treated hepatitis $C$ patients. There were 934 gene regulators identified in this section. The 57 genes regulator correspond to present study were up-regulated (Table 7), and 64 gene regulators down-regulated (Table 8 ). There were several miRNAs (38), which were up-regulated and remaining other important biomarkers gene were down-regulated (Table 8). The activation Z-Scores (3.79-1.26) and $P$-values (5.39E-8 - 1.26) were significant from each biomarkers. The down-regulated biomarkers included several cytokines (IL-2, Il-5, IL-6, IL-7, IL-12, IL-13, IL-15, IL-17, IL-17A, IL-18, IL-21, IL-24, IL-27, IL-32), as well as miRNA-15, miRNA-124, miRNA-218-5P, interferon $\beta-1 \mathrm{a}$, interferon $\gamma$, TNF- $\alpha$, STAT2, NOX1, prostaglandin $\mathrm{J} 2, \mathrm{NF}-\mathrm{kB}$, IкB, and TCF3 (transcription regulator), with significant activation Z-Score (-4.56-2.531), and $P$-values were 9.17-14.00; $P<0.05$, respectively (Table 8 ).

\section{"Diseases or functions annotation" affected by $\delta$-tocotrienol feeding in hepatitis $C$ patients}

The effect of $\delta$-tocotrienol on gene expression in "diseases or functions annotation" of IPA of mRNAs sample of chronic hepatitis $\mathrm{C}$ patients resulted in determining 500 types of diseases and functions. Out of these 11 type genes of diseases and functions were up-regulated, while 49 were down regulated (Table 9A and B). The up-regulated genes (11) of functions include cell death/survival cell death, organismal injury and abnormalities, cellular function and maintenance, gene expression, protein synthesis, metabolic disease, and neurological diseases as shown in Table 9A. Their $p$-values and activation Z-Scores varied from 3.94E218.54E6 2.64-0.71 $(\boldsymbol{P}<0.01)$, respectively (Table 9A). The gene expression of 49 were down-regulated after $\delta$-tocotrienol treatment of chronic hepatitis $\mathrm{C}$ patients. These genes are involved in cellular development, cellular growth, proliferation hematology, infectious diseases, cell-to-cell signaling/interaction, cardiovascular disease, antimicrobial response, cell morphology, inflammatory response, neurological disease, humoral immune response, free radical scavenging, immunological diseases, lipid metabolism, gene expression, cancer, RNA post-transcriptional modification and many other diseases as outlined in Table 9B.

The results described so far are summarized in Table 10. The data were divided into 12 categories, each 
Table 3 Effect of $\delta$-tocotrienol on down-regulation of fold change gene expression of "Molecules" section (64) of IPA analysis in hepatitis $C$ patients

\begin{tabular}{|c|c|c|c|c|}
\hline \multicolumn{5}{|c|}{ Down-regulation } \\
\hline$\#$ & Symbol & Entrez Gene Name & Expr Fold Change & Type(s) \\
\hline 1 & ATP1A1 & ATPase $\mathrm{Na}+/ \mathrm{K}+$ transporting subunit alpha 1 & -8.014 & transporter \\
\hline 2 & HSP90AB1 & heat shock protein 90 alpha family class B member 1 & -8.049 & enzyme \\
\hline 3 & APOBEC $3 \mathrm{~A}$ & apolipoprotein B mRNA editing enzyme catalytic subunit $3 \mathrm{~A}$ & -8.163 & enzyme \\
\hline 4 & CXCR2 & C-X-C motif chemokine receptor 2 & -8.208 & G-protein coupled receptor \\
\hline 5 & IL16 & interleukin 16 & -8.239 & cytokine \\
\hline 6 & PSMC3 & proteasome $26 \mathrm{~S}$ subunit, ATPase 3 & -8.346 & transcription regulator \\
\hline 7 & NDUFB9 & NADH:ubiquinone oxidoreductase subunit B9 & -8.354 & enzyme \\
\hline 8 & CYB5R4 & cytochrome b5 reductase 4 & -8.367 & enzyme \\
\hline 9 & ATG3 & autophagy related 3 & -8.376 & enzyme \\
\hline 10 & CREB1 & CAMP responsive element binding protein 1 & -8.452 & transcription regulator \\
\hline 12 & NDUFB1 & NADH:ubiquinone oxidoreductase subunit B1 & -8.566 & enzyme \\
\hline 13 & PDE3B & phosphodiesterase 3B & -8.568 & enzyme \\
\hline 14 & IGF2R & insulin like growth factor 2 receptor & -8.68 & transmembrane receptor \\
\hline 15 & CYP2R1 & cytochrome P450 family 2 subfamily R member 1 & -8.682 & enzyme \\
\hline 16 & NDUFA11 & NADH:ubiquinone oxidoreductase subunit A11 & -8.686 & enzyme \\
\hline 17 & IGSF6 & immunoglobulin superfamily member 6 & -8.712 & transmembrane receptor \\
\hline 18 & TNFRSF1B & TNF receptor superfamily member $1 \mathrm{~B}$ & -8.746 & transmembrane receptor \\
\hline 19 & PRPF18 & pre-mRNA processing factor 18 & -8.777 & transporter \\
\hline 20 & SERP1 & stress associated endoplasmic reticulum protein 1 & -8.872 & other \\
\hline 21 & UBE2J1 & ubiquitin conjugating enzyme E2 J1 & -8.874 & enzyme \\
\hline 22 & VEGFA & vascular endothelial growth factor A & -8.933 & growth factor \\
\hline 23 & GYS1 & glycogen synthase 1 & -9.027 & enzyme \\
\hline 24 & GPR65 & G protein-coupled receptor 65 & -9.054 & G-protein coupled receptor \\
\hline 25 & ILF2 & interleukin enhancer binding factor 2 & -9.105 & transcription regulator \\
\hline 26 & OSBPL11 & oxysterol binding protein like 11 & -9.201 & other \\
\hline 27 & PSMA5 & proteasome subunit alpha 5 & -9.31 & peptidase \\
\hline 28 & PIAS1 & protein inhibitor of activated STAT 1 & -9.326 & transcription regulator \\
\hline 29 & TRAF7 & TNF receptor associated factor 7 & -9.341 & enzyme \\
\hline 30 & $\operatorname{cox} 14$ & COX14, cytochrome c oxidase assembly factor & -9.447 & other \\
\hline 31 & RPS26 & ribosomal protein \$26 & -9.456 & other \\
\hline 32 & SFPQ & splicing factor proline and glutamine rich & -9.469 & other \\
\hline 33 & ATF4 & activating transcription factor 4 & -9.515 & transcription regulator \\
\hline 34 & PECAM1 & platelet and endothelial cell adhesion molecule 1 & -9.552 & other \\
\hline 35 & GPS2 & $\mathrm{G}$ protein pathway suppressor 2 & -9.56 & transcription regulator \\
\hline 36 & NFIL3 & nuclear factor, interleukin 3 regulated & -9.568 & transcription regulator \\
\hline 37 & PSMB8 & proteasome subunit beta 8 & -9.709 & peptidase \\
\hline 38 & UBP1 & upstream binding protein 1 (LBP-1a) & -9.718 & transcription regulator \\
\hline 39 & RAP2C & RAP2C, member of RAS oncogene family & -9.792 & enzyme \\
\hline 40 & PIBF1 & progesterone immunomodulatory binding factor 1 & -9.876 & other \\
\hline 41 & USP25 & ubiquitin specific peptidase 25 & -9.911 & peptidase \\
\hline 42 & FRS2 & fibroblast growth factor receptor substrate 2 & -9.962 & kinase \\
\hline 43 & PSMB4 & proteasome subunit beta 4 & -10.119 & peptidase \\
\hline
\end{tabular}


Table 3 Effect of $\delta$-tocotrienol on down-regulation of fold change gene expression of "Molecules" section (64) of IPA analysis in hepatitis $C$ patients (Continued)

\begin{tabular}{|c|c|c|c|c|}
\hline \multicolumn{5}{|c|}{ Down-regulation } \\
\hline \# & Symbol & Entrez Gene Name & Expr Fold Change & Type(s) \\
\hline 44 & USP15 & ubiquitin specific peptidase 15 & -10.16 & peptidase \\
\hline 45 & UBA52 & ubiquitin A-52 residue ribosomal protein fusion product 1 & -10.176 & enzyme \\
\hline 46 & UBE4A & ubiquitination factor E4A & -10.189 & enzyme \\
\hline 47 & GTPBP8 & GTP binding protein 8 (putative) & -10.19 & other \\
\hline 48 & USP19 & ubiquitin specific peptidase 19 & -10.713 & peptidase \\
\hline 49 & TNFAIP8 & TNF alpha induced protein 8 & -10.974 & other \\
\hline 50 & HSPA14 & heat shock protein family A (Hsp70) member 14 & -10.978 & peptidase \\
\hline 51 & TLR8 & toll like receptor 8 & -11.975 & transmembrane receptor \\
\hline 52 & IL27RA & interleukin 27 receptor subunit alpha & -12.004 & transmembrane receptor \\
\hline 53 & SCP2 & sterol carrier protein 2 & -13.672 & transporter \\
\hline 54 & IFNGR2 & interferon gamma receptor 2 & -13.844 & transmembrane receptor \\
\hline 55 & ID2 & inhibitor of DNA binding 2, HLH protein & -14.133 & transcription regulator \\
\hline 56 & TUSC2 & tumor suppressor candidate 2 & -15.922 & other \\
\hline 57 & IL2RG & interleukin 2 receptor subunit gamma & -16.787 & transmembrane receptor \\
\hline 58 & IL1R2 & interleukin 1 receptor type 2 & -19.547 & transmembrane receptor \\
\hline 59 & IRF2 & interferon regulatory factor 2 & -22.655 & transcription regulator \\
\hline 60 & PTGS2 & prostaglandin-endoperoxide synthase 2 & -25.841 & enzyme \\
\hline 61 & mir-877 & microRNA 877 & -4497.07 & microRNA \\
\hline 62 & mir-1250 & microRNA 1250 & -4755.79 & microRNA \\
\hline 63 & mir-140 & microRNA 140 & -5668.259 & microRNA \\
\hline 64 & KLRC4-KLRK1/KLRK1 & killer cell lectin like receptor K1 & -1565687.642 & transmembrane receptor \\
\hline
\end{tabular}

category has 5 topics (total 60), and out of these 60 topics, only 13 topics were further investigated in detail for their functions related to present studies. For example, the "diseases and disorder" category (III) includes infectious diseases, immunological diseases, cancer, and organismal injury/abnormalities and tumor morphology (Table 10). The "molecular and cellular functions" category (IV) includes cellular development, cellular growth and proliferation, death/survival, cell-to-cell signal ligand interaction and cellular function and maintenance. Table 10 also includes a list of expression log ratio of 10 up-regulated genes (SNORD15A, SNORA32, SNORA56, SNORA9, SNORA3B, SNORA3A, HIST1H2AD, LINC00305, HHIPL2), and 10 down-regulated genes (HMGN1P3, SNHG25, SNORA67, RPL17-C18orf32, ISY1-RAB43, ARHGEF18, KLRC4-KLRK1/ KLRK1, HIST1H3), MTHFS, SNORA16A) were related to present investigation. At the end, out of 360 "canonical pathways" of IPA of total mRNAs samples of effects of $\delta$-tocotrienol treatment to hepatitis $C$ patients, 33 pathways are selected, which are associated with various signaling and biomarkers relative to present results (Table 11). The heat map (Fig. 2) also depicts same diseases and functions as outlined in Tables 9A, B and 10.

\section{Discussion}

The fold-change gene expression data analyzed by Ingenuity Pathway Analysis describes cellular and biological mechanisms at the molecular level on the effect of $\delta$-tocotrienol in chronic hepatitis $C$ patients. It involves metabolic and cellular processes, mainly associated with catalytic activity of structural molecules. It also reveals an insight of correlation of signaling pathways and transcriptional factors, and subsequently describes inhibition or activation of anti- and pro-inflammatory genes. The results of these functional genomics produced a huge amount of data analyzed by biological networks using differentially gene expression after treatment with $\delta$-tocotrienol to chronic hepatitis $\mathrm{C}$ patients. It predicts possible canonical pathways, upstream regulators, diseases and functional metabolic networks. The differential gene expressions of several biological functions illustrated in the heat map is shown in Fig. 2.

The present data revealed that genes responsible for replication of virus, infection by RNA viruses, infection of tumor cell lines, HIV infection and replication of influenza virus were all down-regulated, while cell death processes were all up-regulated. Moreover, as mentioned 


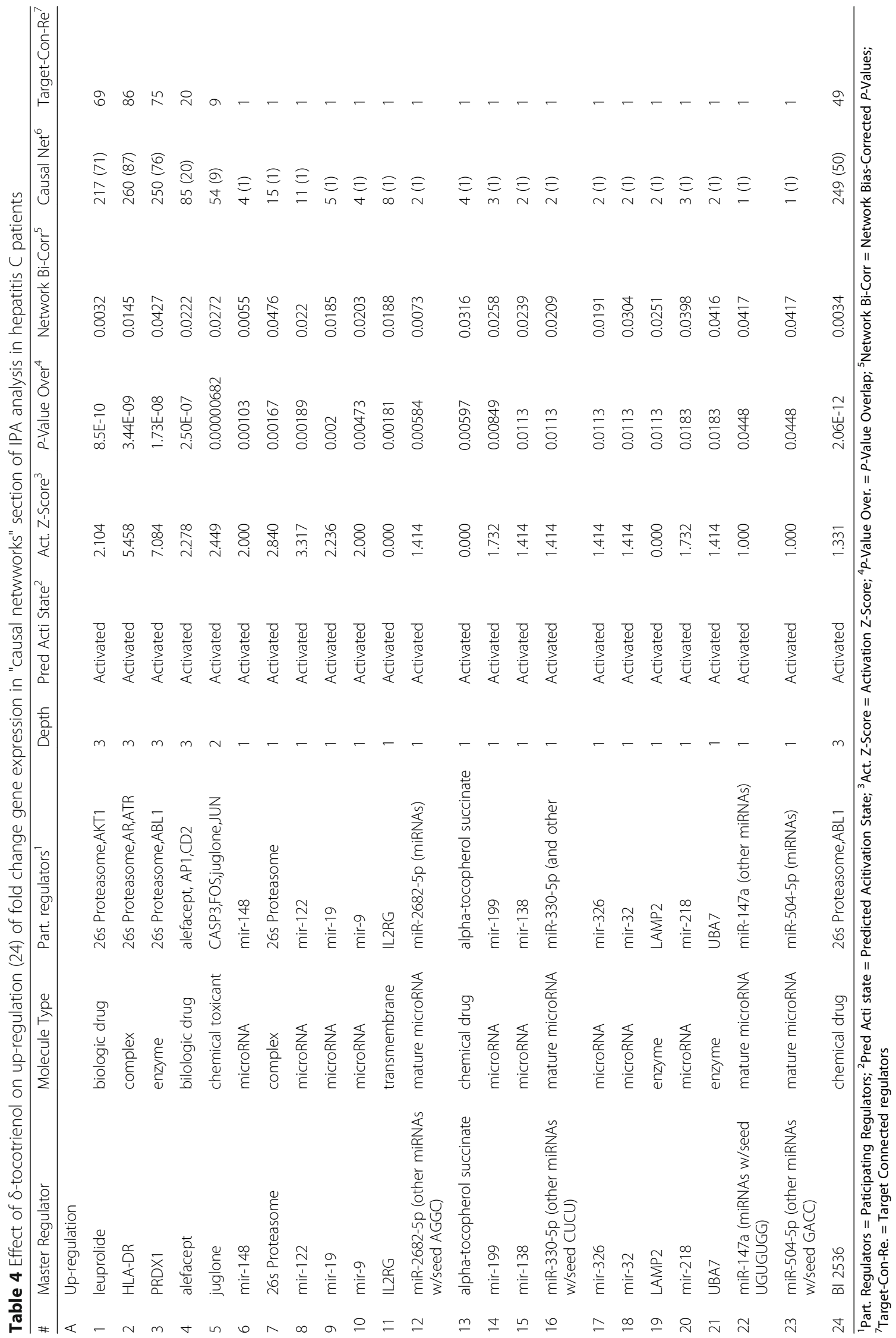




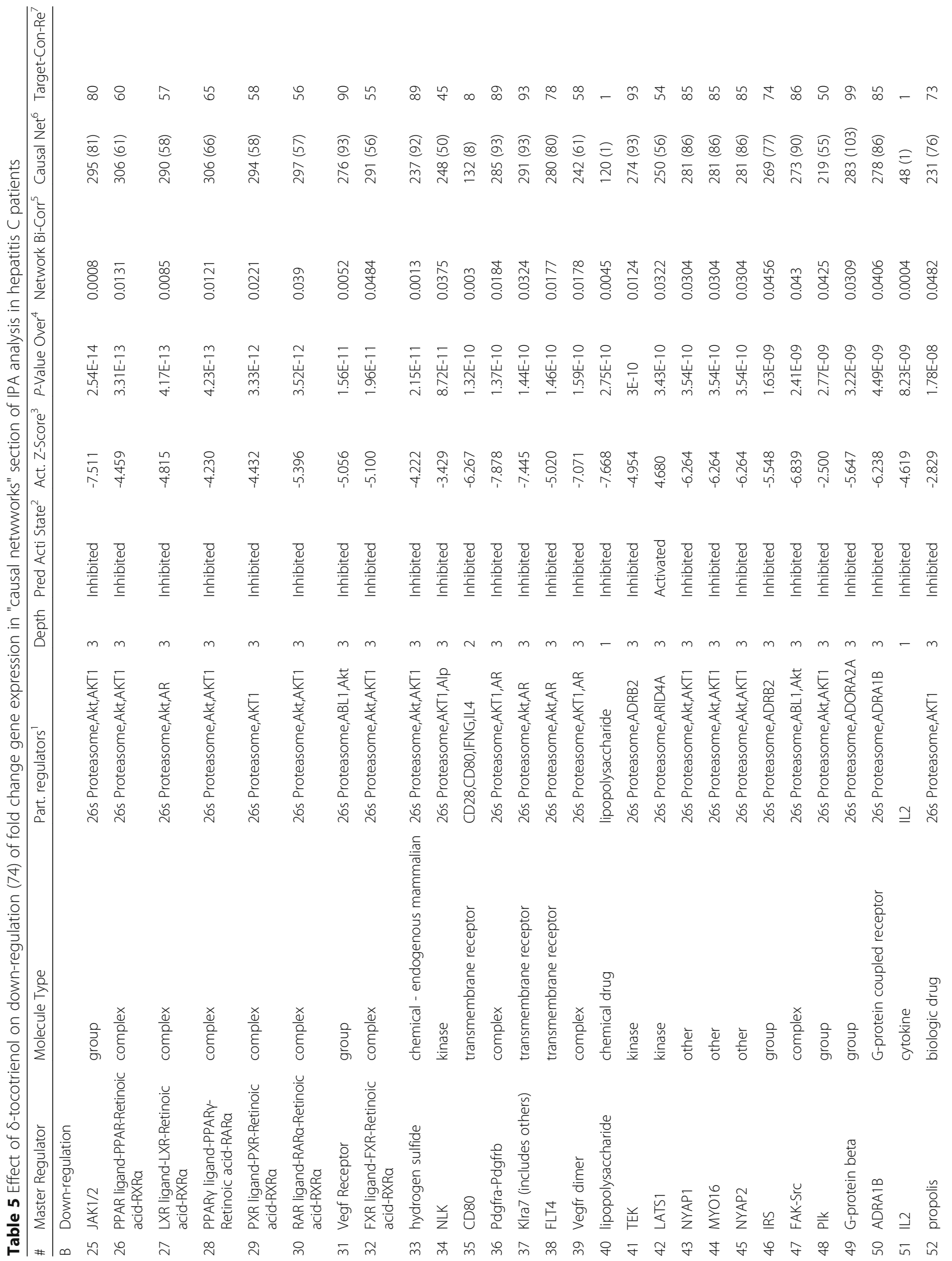




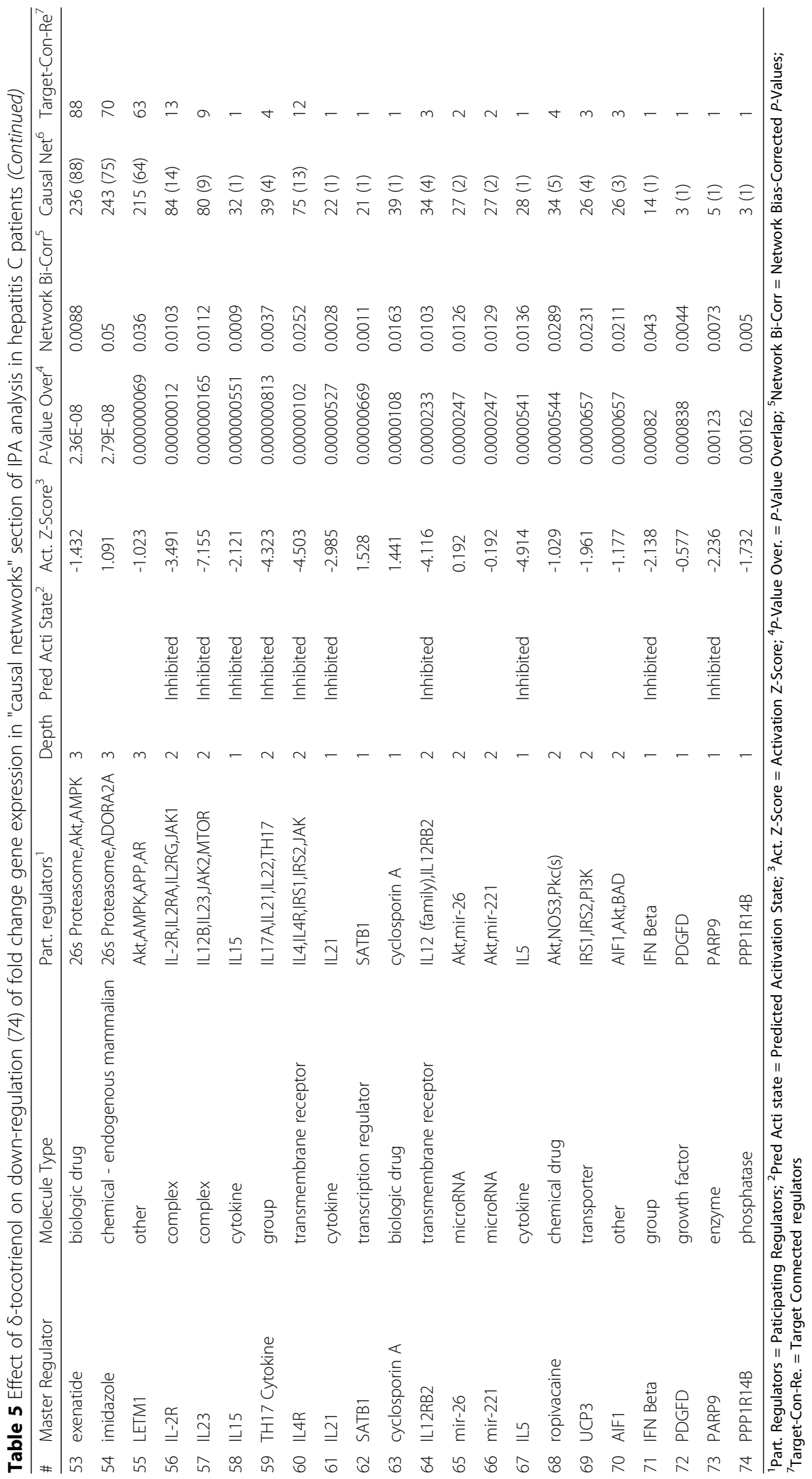




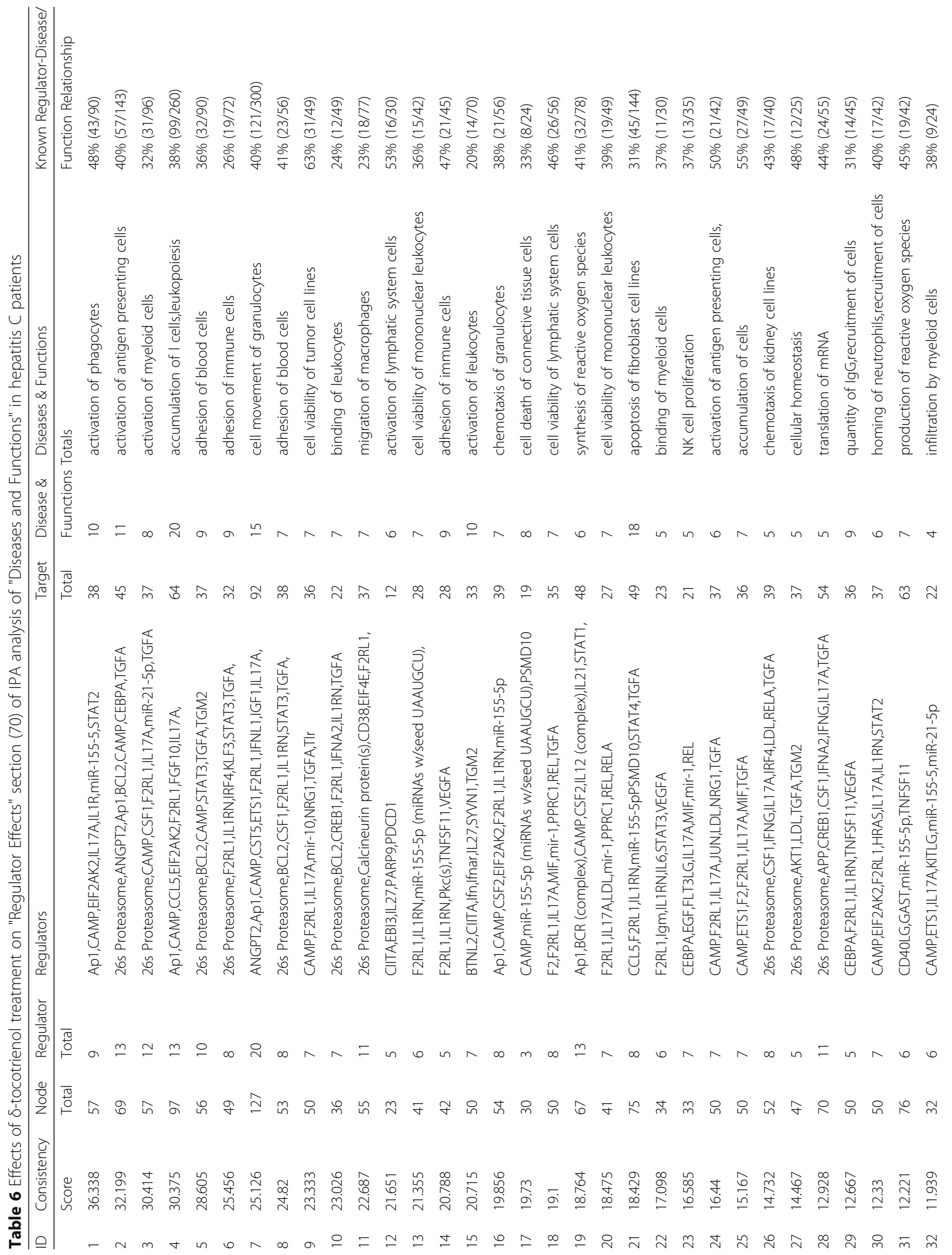




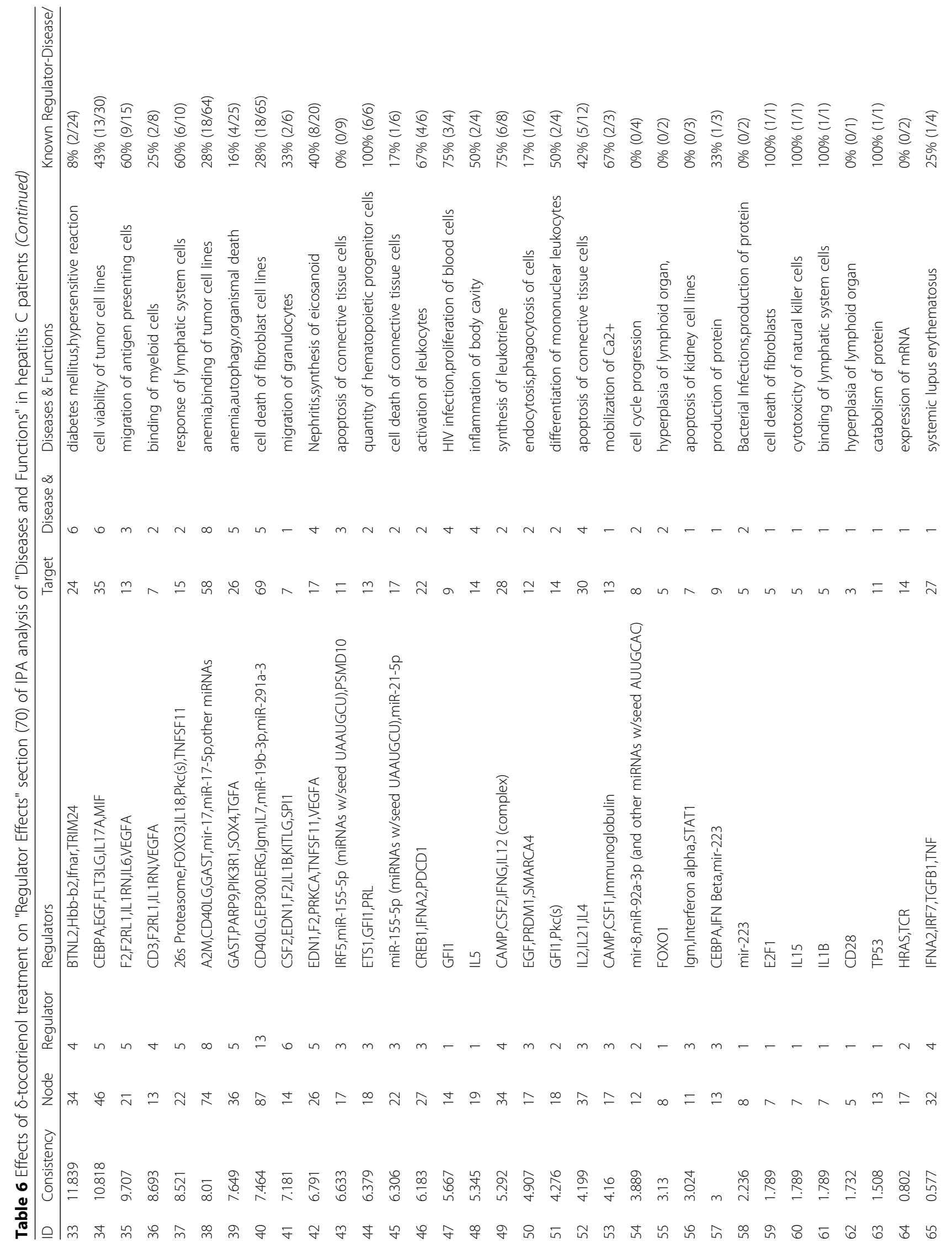




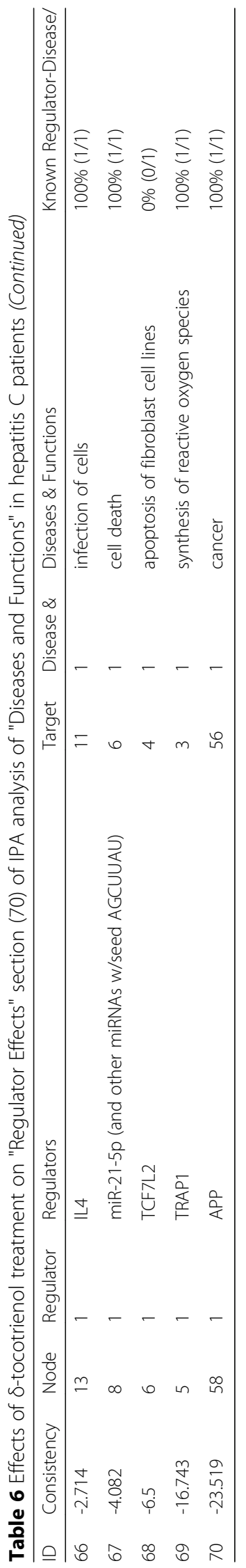




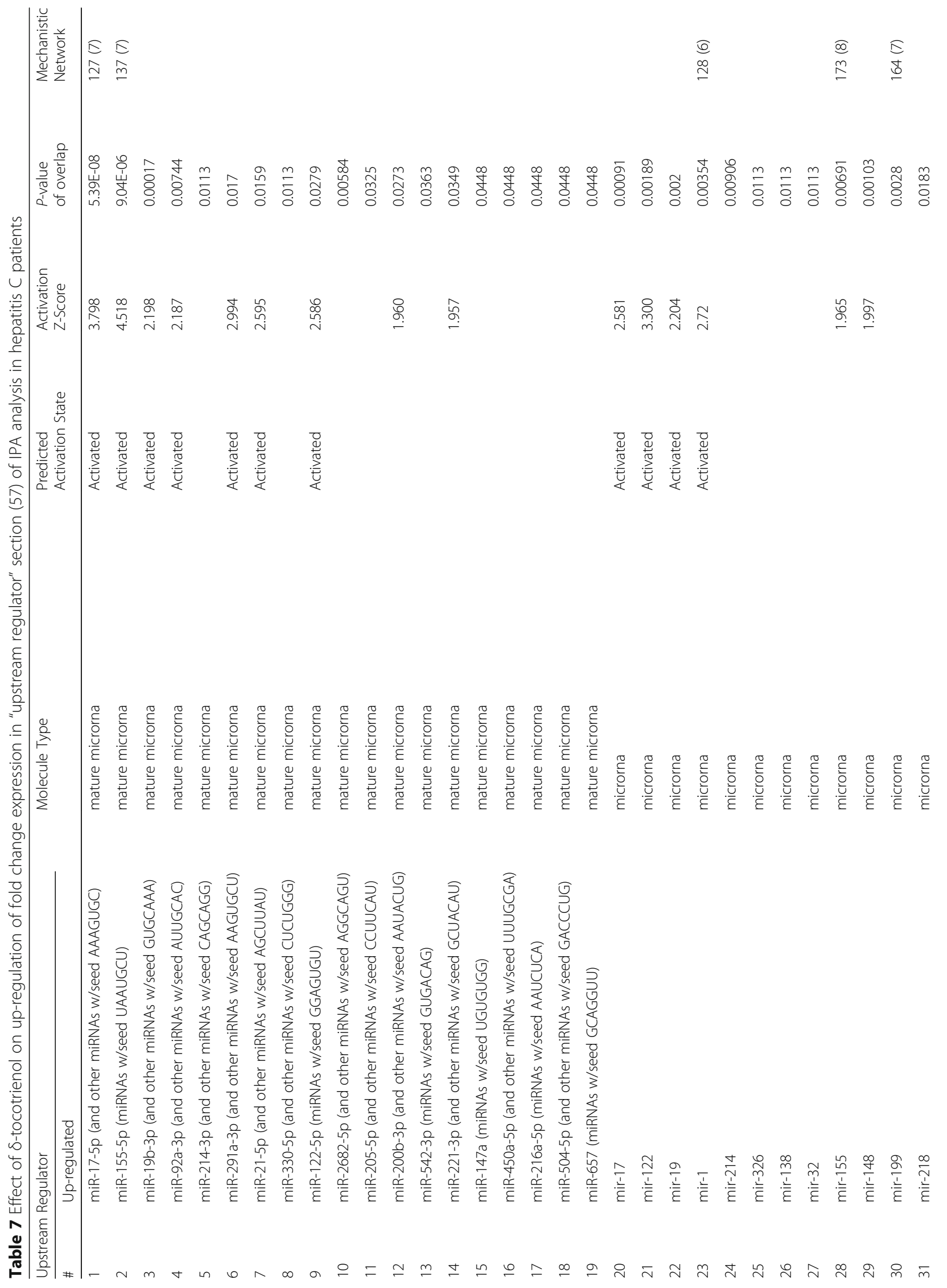




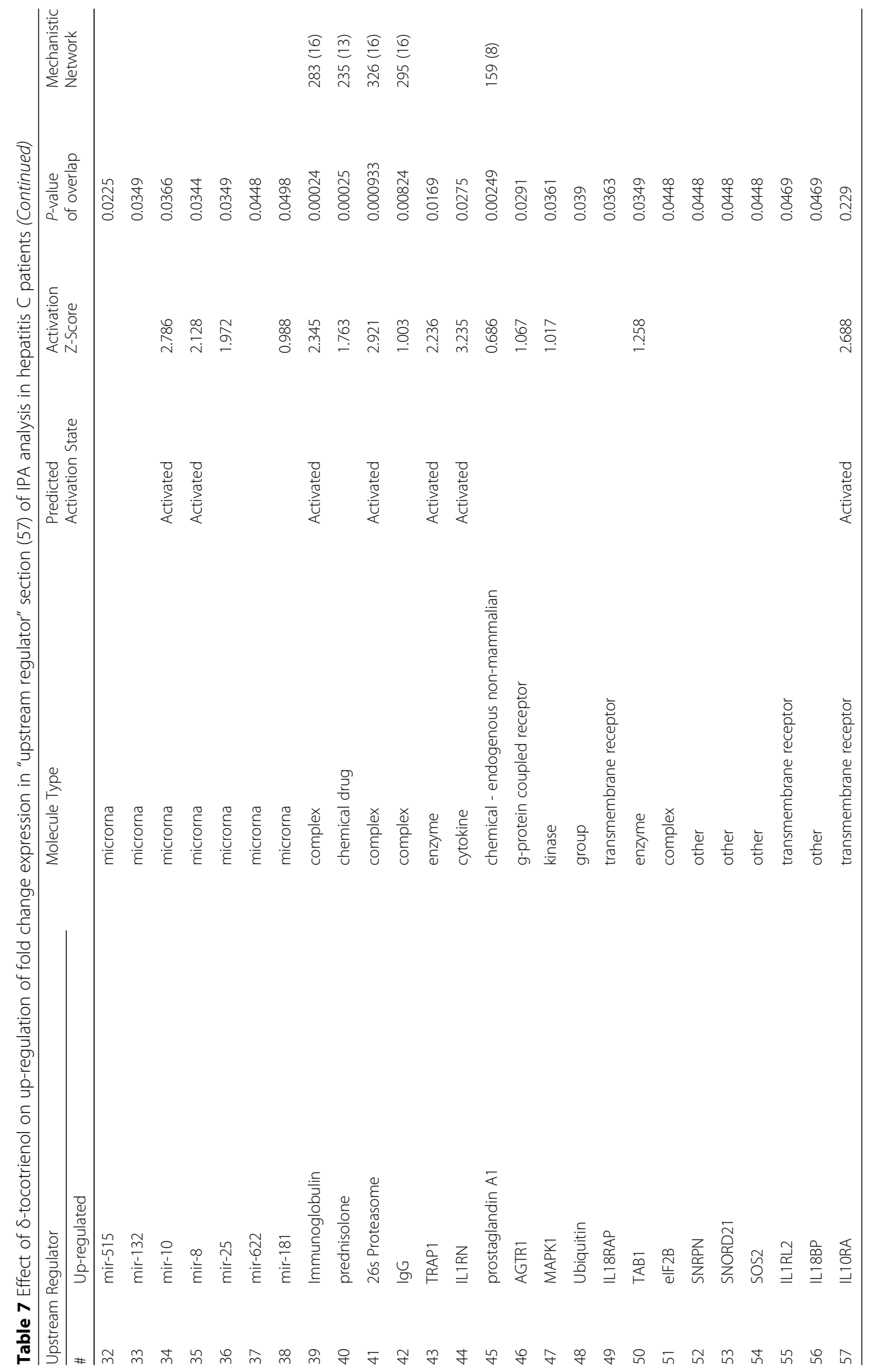




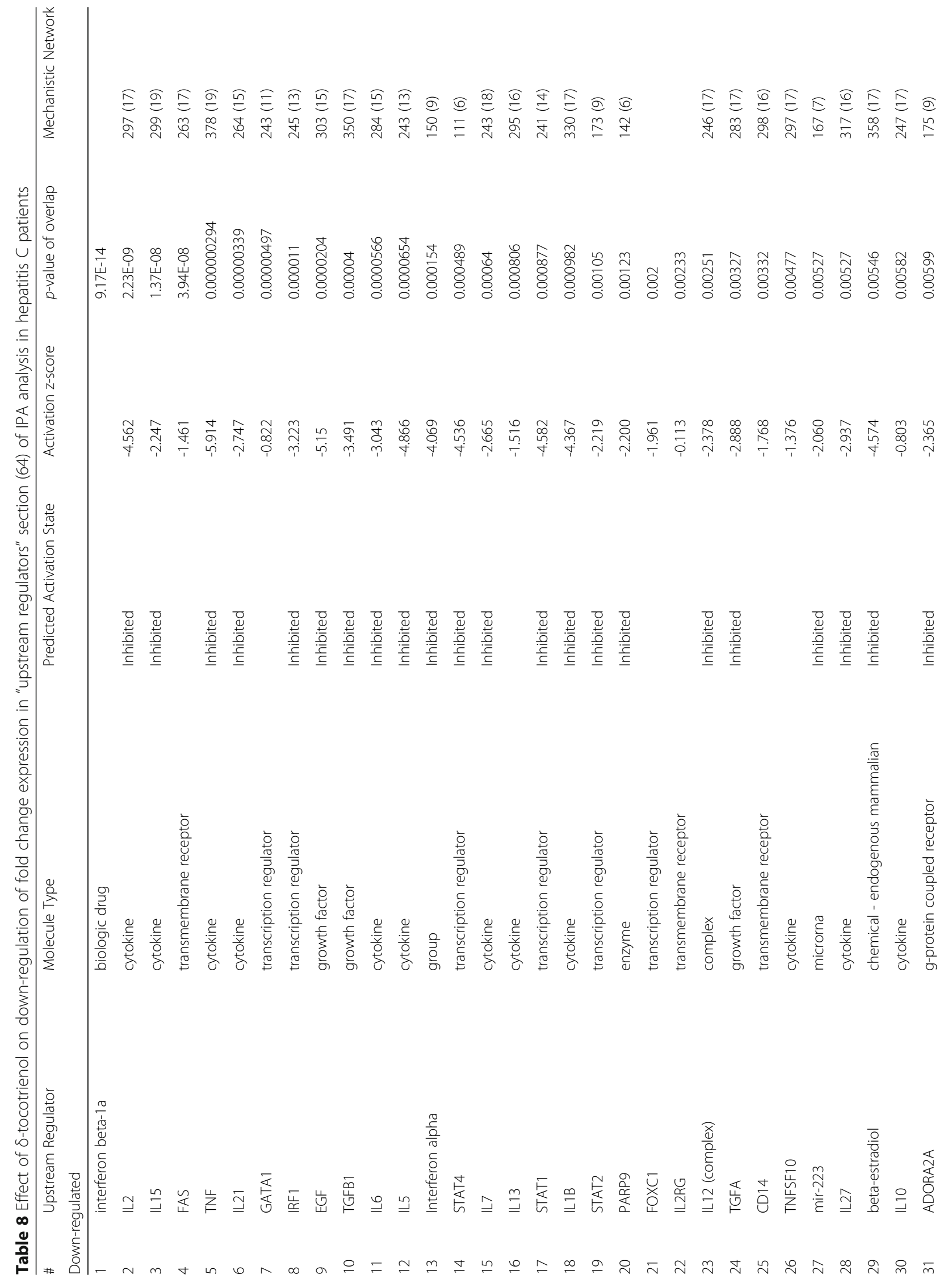




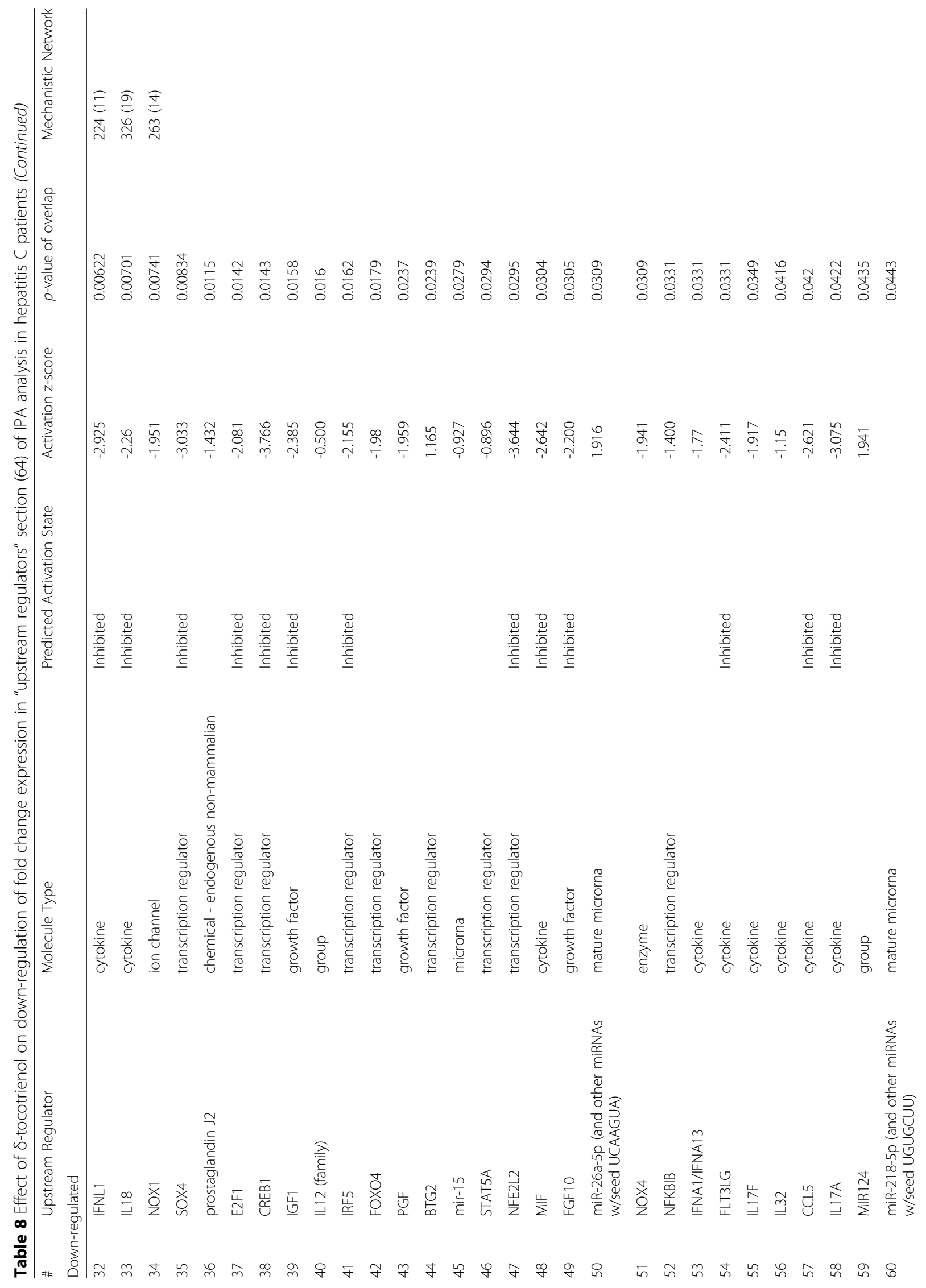




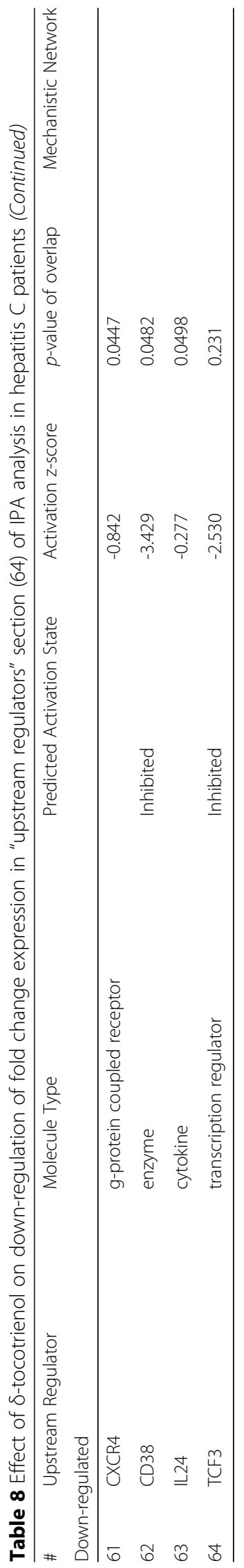




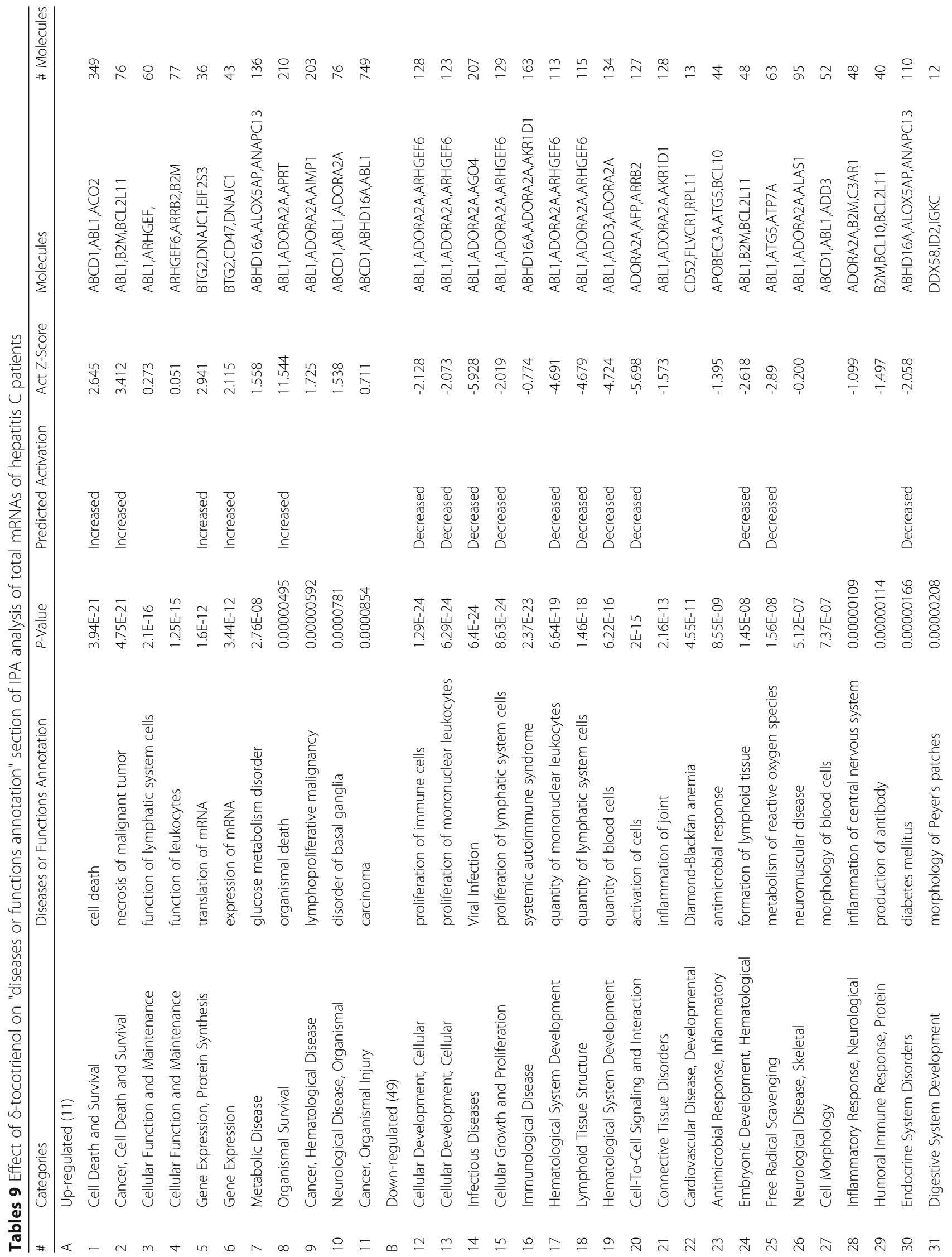




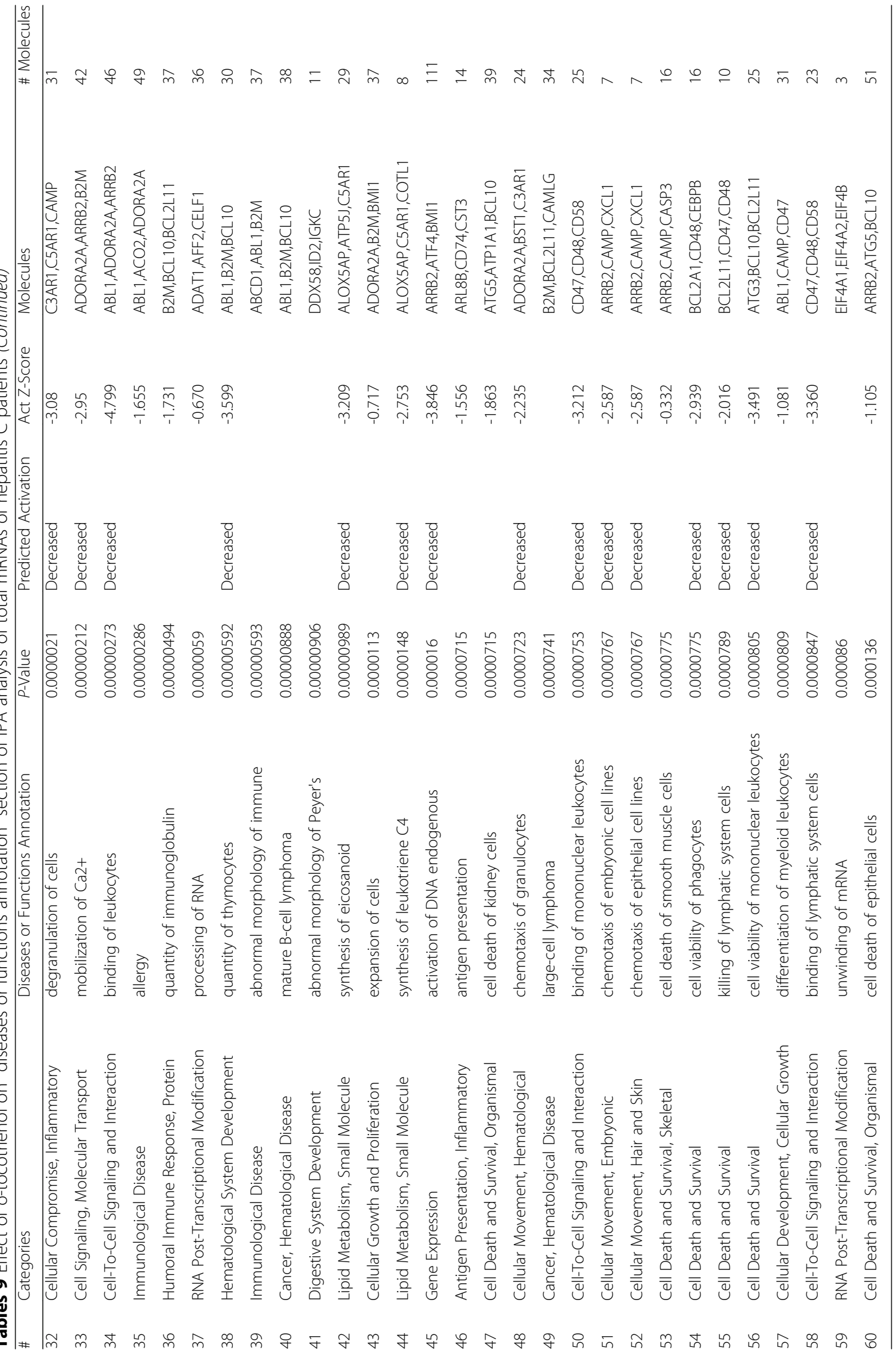




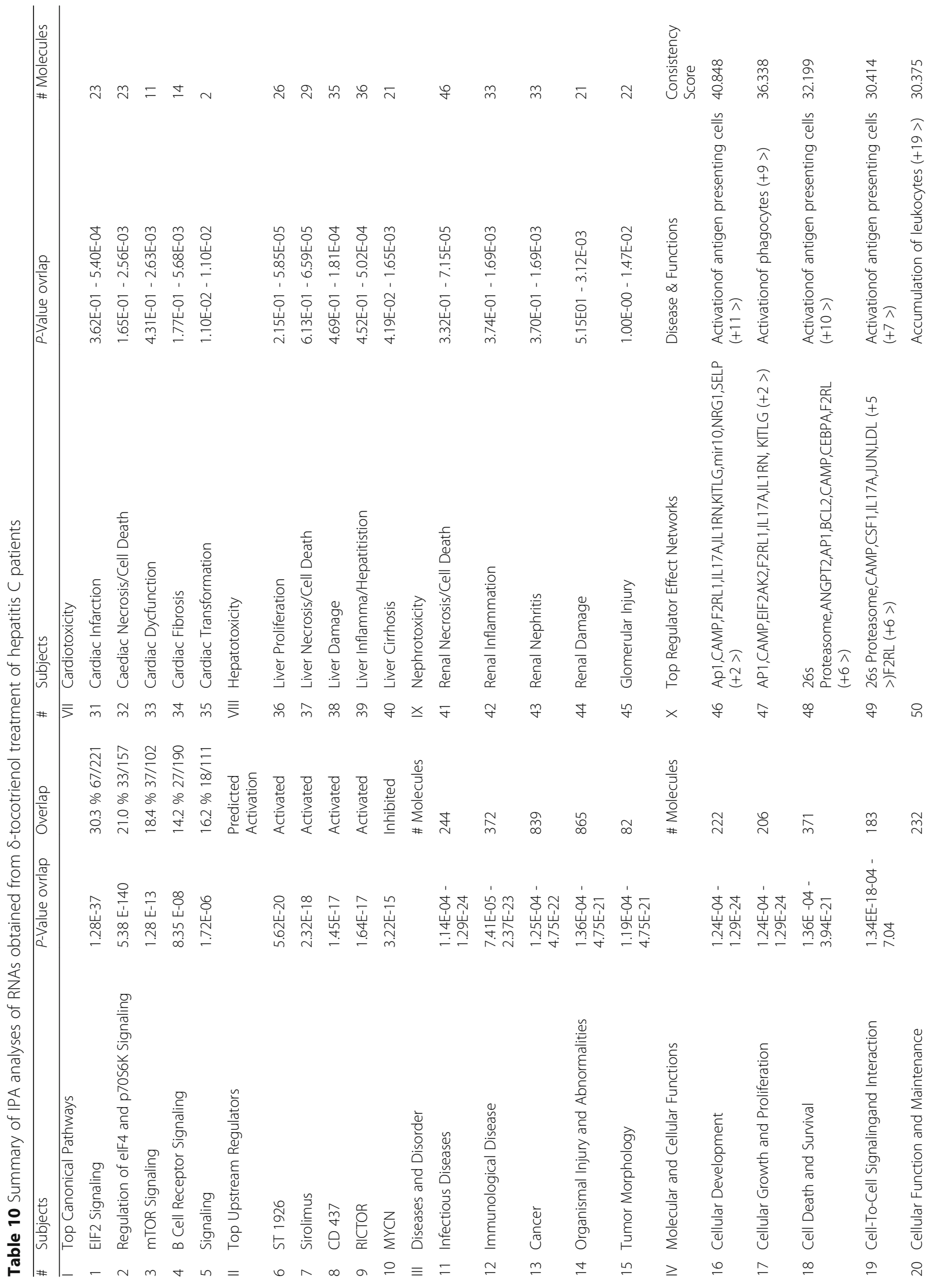




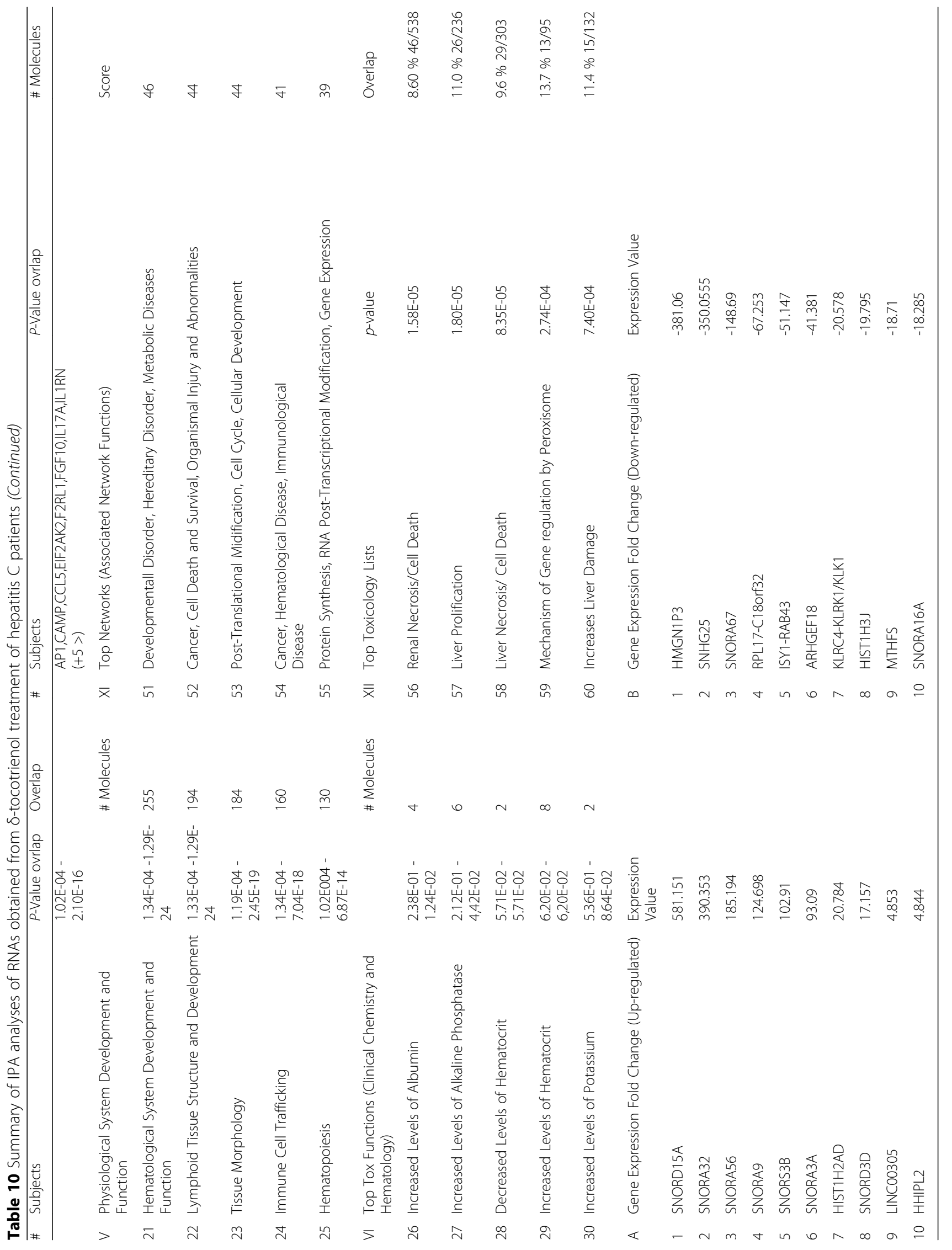




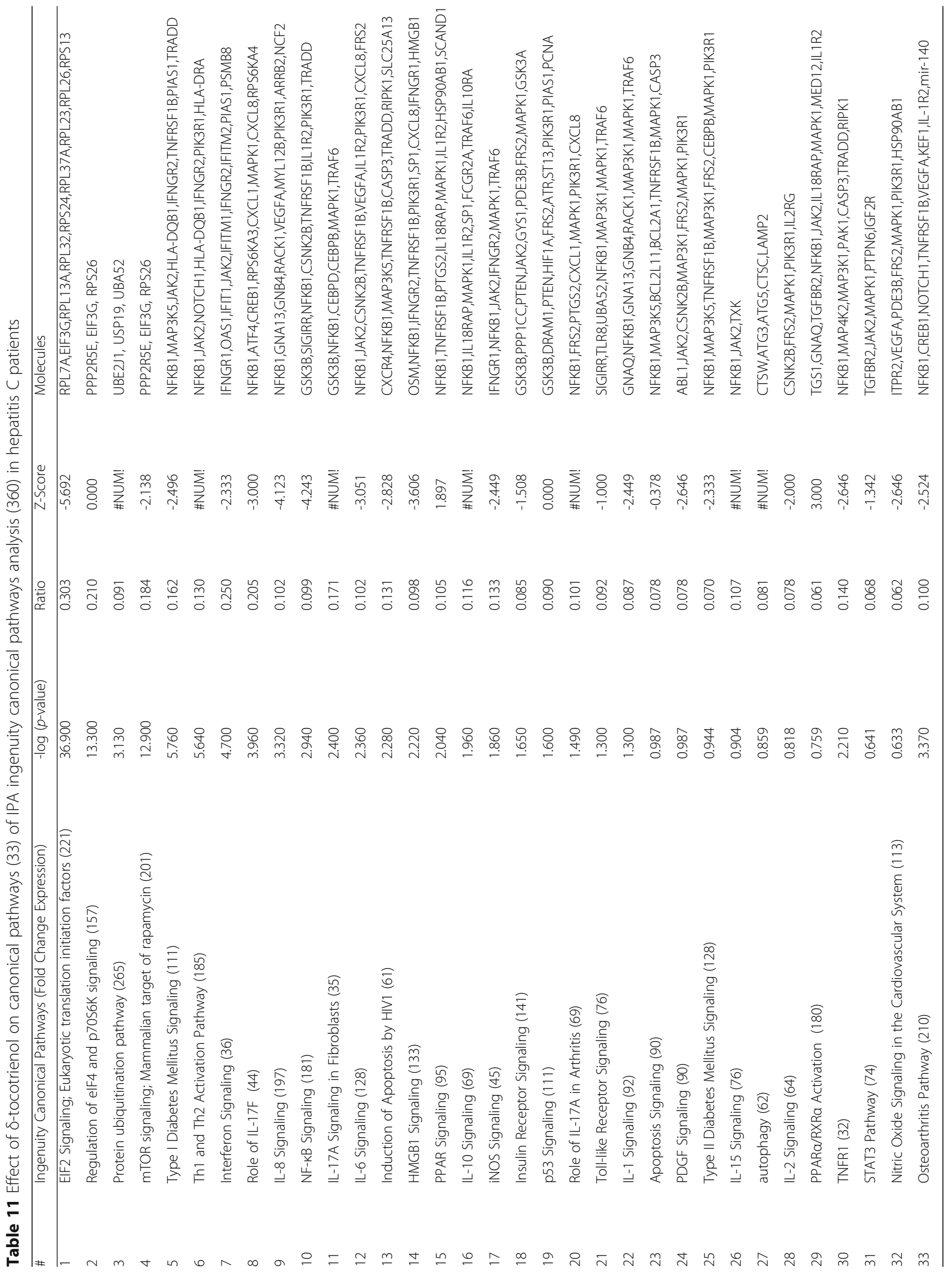


earlier, that Table 10 includes a list of expression log ratio of 10 up-regulated and 10 down-regulated genes. The forgoing information is mainly from "Ingenuity Knowledge Base" including as the information source for these facts and pathways.

The first up-regulated gene, SNORD15 is a non-coding RNA (ncRNA) gene which involves in the modification of other small nuclear RNAs (snRNAs), located in the nucleolus of the eukaryotic cell, which is a major site of snRNA biogenesis, and known as small nuclear RNA (snoRNA) [9]. It belongs to C/D box class of snoRNA, which function in directing site-specific 2-O-methylation of substrate RNAs [9]. In humans, there are two closely related copies of the U15 snoRNA (called SNORD15A and SNORD15B) [10]. Histone H2A type 1-D encoded by HIST1H2AD gene in humans. Histones are basic nuclear proteins that are responsible for the nucleosome structure of chromosomal fiber in eukaryotes. LINC00305 is associated with atherosclerotic plagues and monocytes [11]. Overexpression of LINC00305 promoted the expression of inflammation-associated genes in THP-1cells and reduced the expression of contractile markers in co-cultured human aortic smooth muscle cells. LINC00305 overexpression activated NF- $\mathrm{kB}$ and inhibition of NF- $\mathrm{kB}$ abolished LINC00305-mediated activation of cytokine expression [12]. HHIPL-2 identified as a candidate gene involved in iron-related modulation of osteoblast markers. The excess of iron limits HHIP-2 gene expression and decreases osteoblastic activity in human MG-63 cell [13].

Whereas, the "High Mobility group Nucleosome Domain 1 Pseudogene 3" (HMGN1P3) is a down-regulated pseudogene 3, and belongs to NURSA nuclear receptor

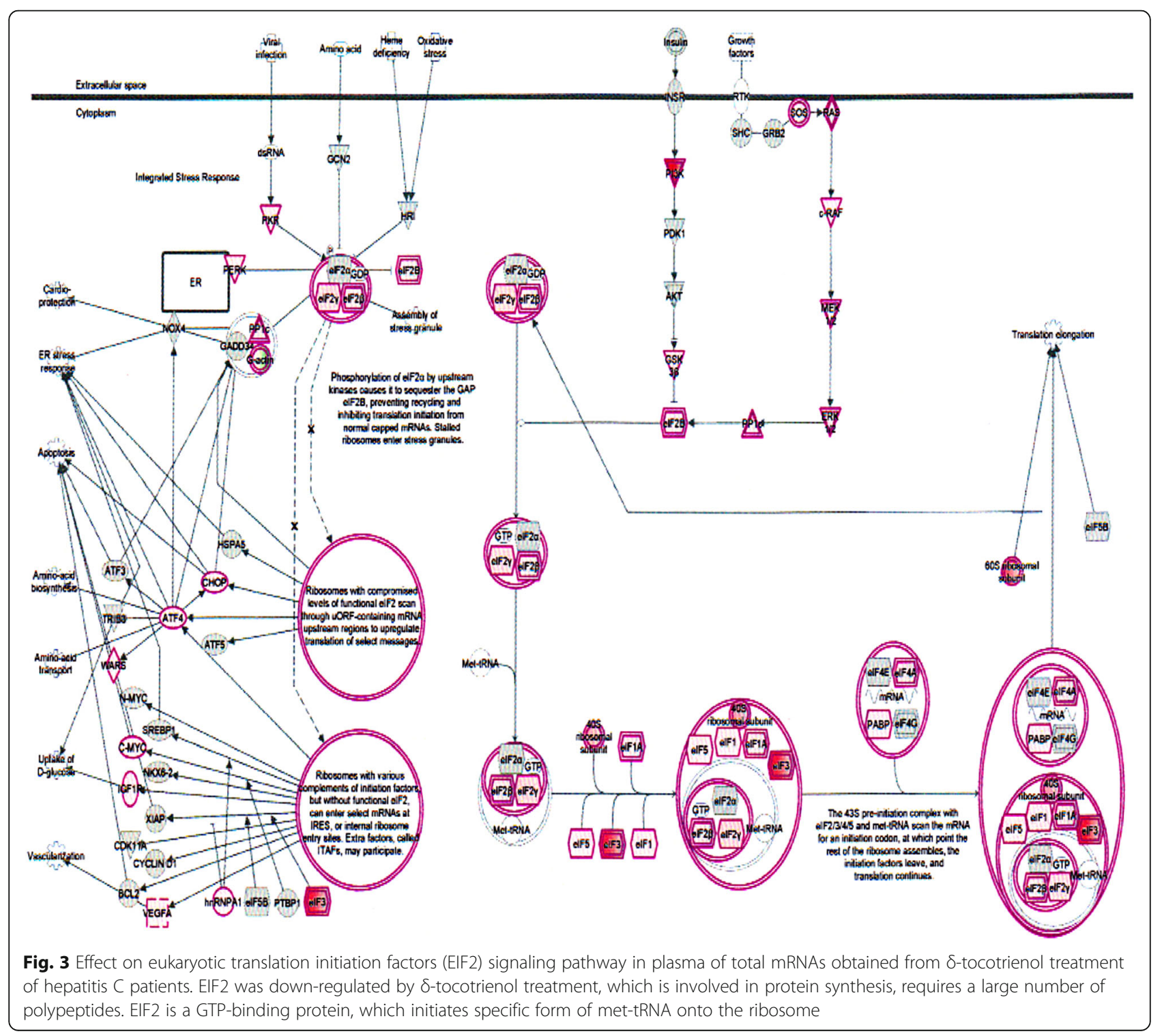


signaling pathways expression of HMGN1P3 gene, and involves in all type of cancers (from breast, prostate, pancreas, colon kidney, lung, ovary, uterus) $[14,15]$. The small nuclear RNA (SNORA67) is also a down-regulated non-coding RNA molecule that belongs to the H/ACA class of snoRNA, which guide the sites of modification of uridines and pseudouridines [16]. The ISY1-RAB43 is the naturally occurring read-through transcription gene, which act between the neighboring ISY1 (splicing factor homolog) and RAB43 (member RAS oncogene family) gene on chromosome 3 . The read-through transcript encodes is a protein that shares sequence identity with the upstream gene product, but its C-terminus is distinct due to a frameshift relative to the downstream gene [17]. The Rho/Rac guanine nucleotide exchange factor 18 (ARHGEF18) is GTP binding proteins that regulate a number of cellular functions such as, cytoskeletal rearrangements, gene transcription, cell growth and motility [18].

The KLRC4-KLRK1 gene represents also naturally occurring down-regulated read-through transcription gene, which acts between the neighboring KLRK4 (killer cell lectin-like receptor subfamily $\mathrm{C}$, member 4 ) family. This protein and its ligands are therapeutic targets for the treatment of immune diseases and cancers [19]. Histone H3.1 is a protein that in human encoded by the HIST1H3J gene [20, 21]. Histones are basic nuclear proteins that are responsible for the nucleosomes fiber in eukaryotes. The methenyltetrahydrofolate synthetase (MTHFS) is down- regulated encoded an enzyme that catalyzes the conversion of 5 -formyltetrahydrofolate to 5, 10-methenyltetrahydrofolate, and helps regulate carbon flow through the folate-dependent one-carbon metabolic

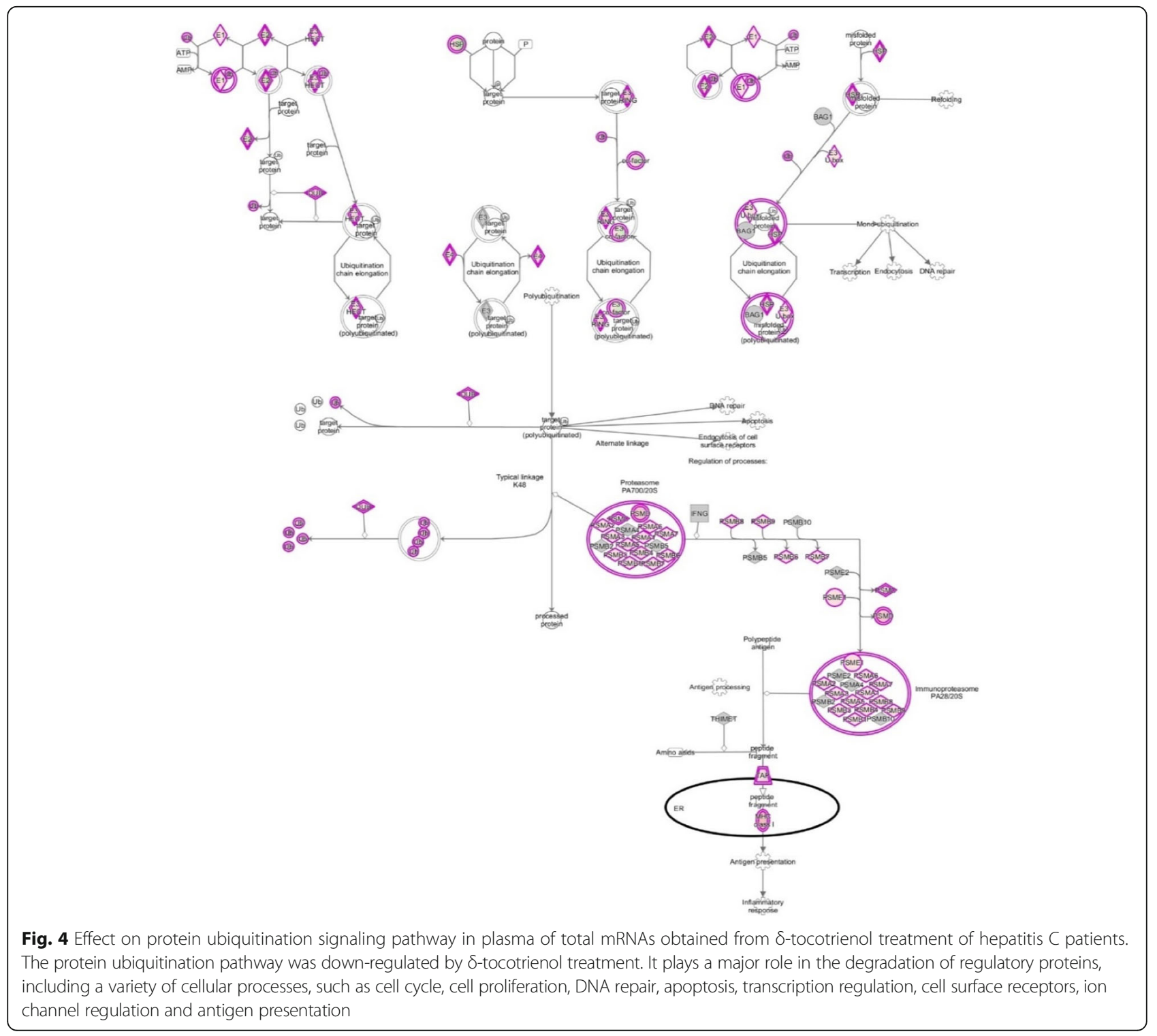


network [22, 23]. The small nucleolar RNA, H/ACA box 16A (SNORA16A) gene provides a unified query environment for genes defined by sequence [24].

The study also provides an insight of correlation of signaling pathways and transcriptional factors and subsequently describes the modulation of anti- as well as pro-inflammatory genes. It described the effects $\delta$-tocotrienol in chronic hepatitis $\mathrm{C}$ patients on gene expression of liver cancer, liver hyperplasia, cell proliferation, cell growth, cell death/survival, infections, inflammatory diseases, and apoptosis. Collectively, the effects of $\delta$-tocotrienol on "canonical pathways" observed in IPA of total mRNA sample of hepatitis $C$ patients resulted in modulation of over 360 pathways, which are associated with multiple signaling pathways. It is conceivable that some or most of these pathways may be controlled by the proteasome, since the protein ubiquitination pathway was down-regulated by $\delta$-tocotrienol treatment as described previously [1].
The important signaling pathways modulated by tocotrienols are as follows: at the top of the list is "eukaryotic translation initiation factors" (EIF2) signaling pathway (Fig. 3). This is involved in protein synthesis, and requires a large number of polypeptides. EIF2 is a GTP-binding protein, which initiates specific forms of met-tRNA onto the ribosome. Its important function is to deliver charged initiator met-tRNA to the ribosome, it also identifies the translational starting site [9]. This is followed by protein ubiquitination pathway, which plays a major role in the degradation of short-lived or regulatory proteins. It plays a role in a variety of cellular processes, such as cell cycle, cell proliferation, apoptosis, DNA repair, transcriptional regulation, cell surface receptors, ion channels regulation and antigen presentation, as outlined in Fig. 4 [10]. We have discussed the importance of ubiquitination in our several earlier publications [11-15].

$\delta$-Tocotrienol treatment of chronic hepatitis $\mathrm{C}$ patients also affects several other regulators in canonical pathways,

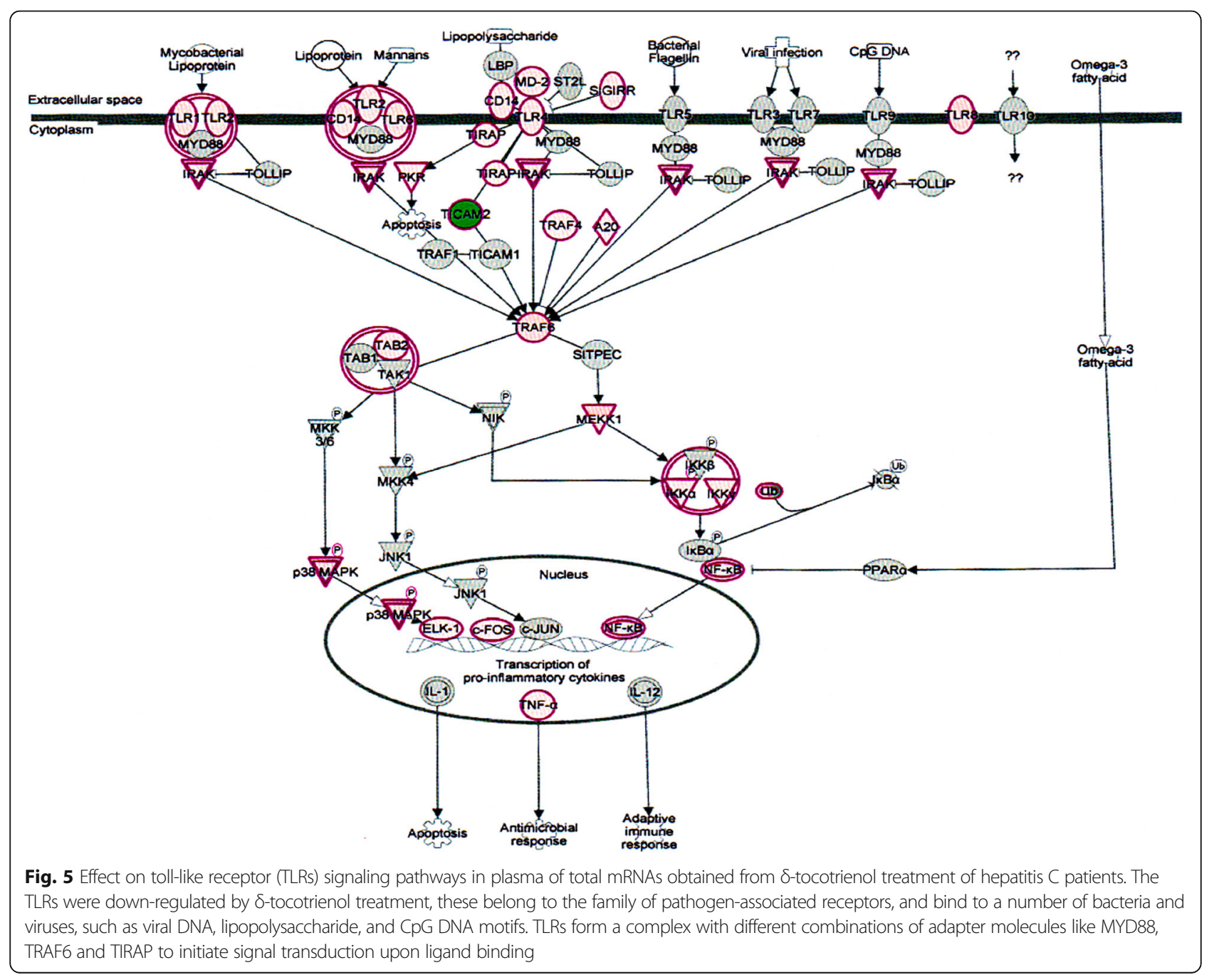


we will limit our discussion to only important signaling and biomarkers associated with present investigation. The toll-like receptor signaling (TLRs) belongs to the family of pathogen-associated pattern recognition receptors, and bind to specific molecular patterns in bacteria and viruses. The pathogen-associated ligands include bacterial flagellin, viral DNA, lipopolysaccharide (LPS) and CpG DNA motifs. TLRs form a complex with different combinations of adopter molecules like MYD88, TRAF6 and TIRAP to initiate signal transduction upon ligand binding. This binding triggers a cascade of signaling events via the TLR-adapter complex, and downstream sigling molecules like p38MAPK. JNK. NF-кB activated and translocated into the nucleus, where they activate transcription regulators like c-Fos and c-Jun, leading to the induction of several pro-inflammatory cytokines, eventually leading to antibacterial and antiviral responses $[25,26]$. Tocotrienol treatment causes a downregulation of the TLR pathways in hepatitis $\mathrm{C}$ patients. The toll-like receptor signaling pathways outlined in Fig. 5.

The signal transducers and activators of transcription (STATs) are a family of cytoplasmic proteins with Src homology-2 (SH2) domains. STATs acts as a signal messenger and transcription factors. It participates in normal cellular responses to cytokines and growth factors. STATs pathways activated via tyrosine phosphorylation cascade after ligand binding by stimulation of the cytokine receptor-kinase complex and growth factor-receptor complex. The IL-6 cytokine activates STAT3 and STAT1. STAT3 encoded in human gene. The STAT3 signaling pathway (Fig. 6) plays an important role in normal development, particularly hematopoiesis, and regulates cancer metastasis by regulating the expression of genes that are critical to cell survival, cell proliferation, invasion, angiogenesis, and tumor immune evasion [27-29].

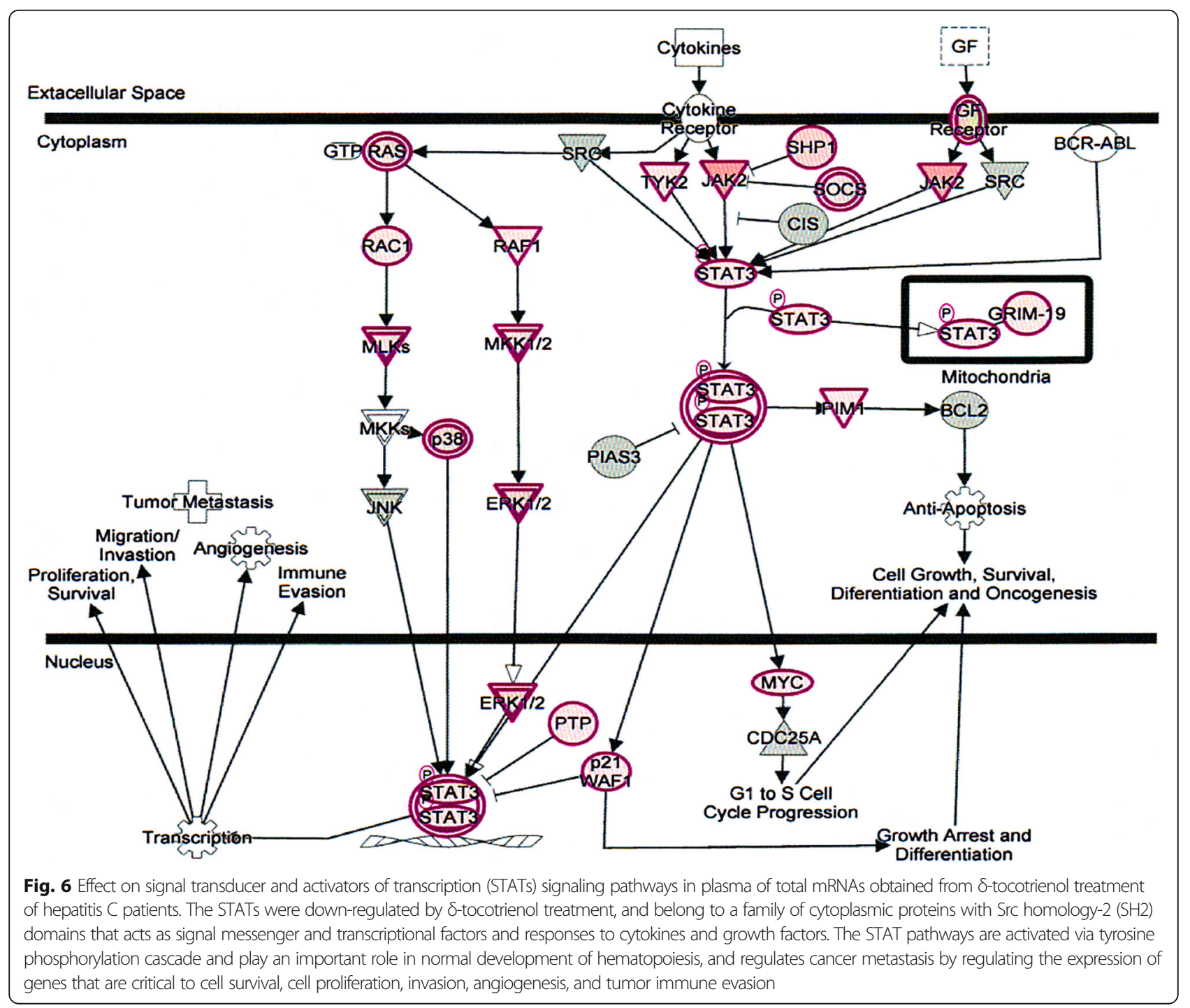


The nuclear factor kappa B (NF-kB) transcription factors are key regulators of gene expression and acts in response to stress and the development of innate and acquired immunity [30]. A multitude of extracellular stimuli (such as cytokines, infections, oxidative, DNA-damaging agents, UV light, osmotic shock) can lead to NF- $\mathrm{kB}$ activation. NF- $\mathrm{kB}$ activators mediate the site-specific phosphorylation of serine on IкB (inhibitor of NF- $\kappa B$ ), resulting in IкB ubiquitination and subsequent proteasomal destruction [31]. The pathway highlights the important components of the NF- $\mathrm{kB}$ signaling pathway outlined in (Fig. 7). Inhibiting this pathway by proteasome inhibitors would possibly expected to cause cell death of infected hepatic cells.
The catalytic activity of iNOS is to kill or inhibit the growth of invading viruses and microorganisms. It produces nitric oxide from L-arginine [32, 33]. Nitric oxide is a free radical effector of the innate immune system that can directly inhibit pathogen replication. A variety of extracellular stimuli can activate signaling pathways that converge to initiate expression of iNOS. Moreover, components of cell wall of bacteria (lipopolysaccharide; LPS) or fungi trigger the innate immune signaling cascade leading to expression of iNOS [34-36]. This leads to activation of NF- $\mathrm{kB}$ and $\mathrm{p} 38$ MAPK signaling pathways [37]. NF- $k B$ in the nucleus binds to NF- $k B$ elements in the iNOS $5^{\prime}$ flanking region, triggering iNOS transcription. Cytokines released from the infected host

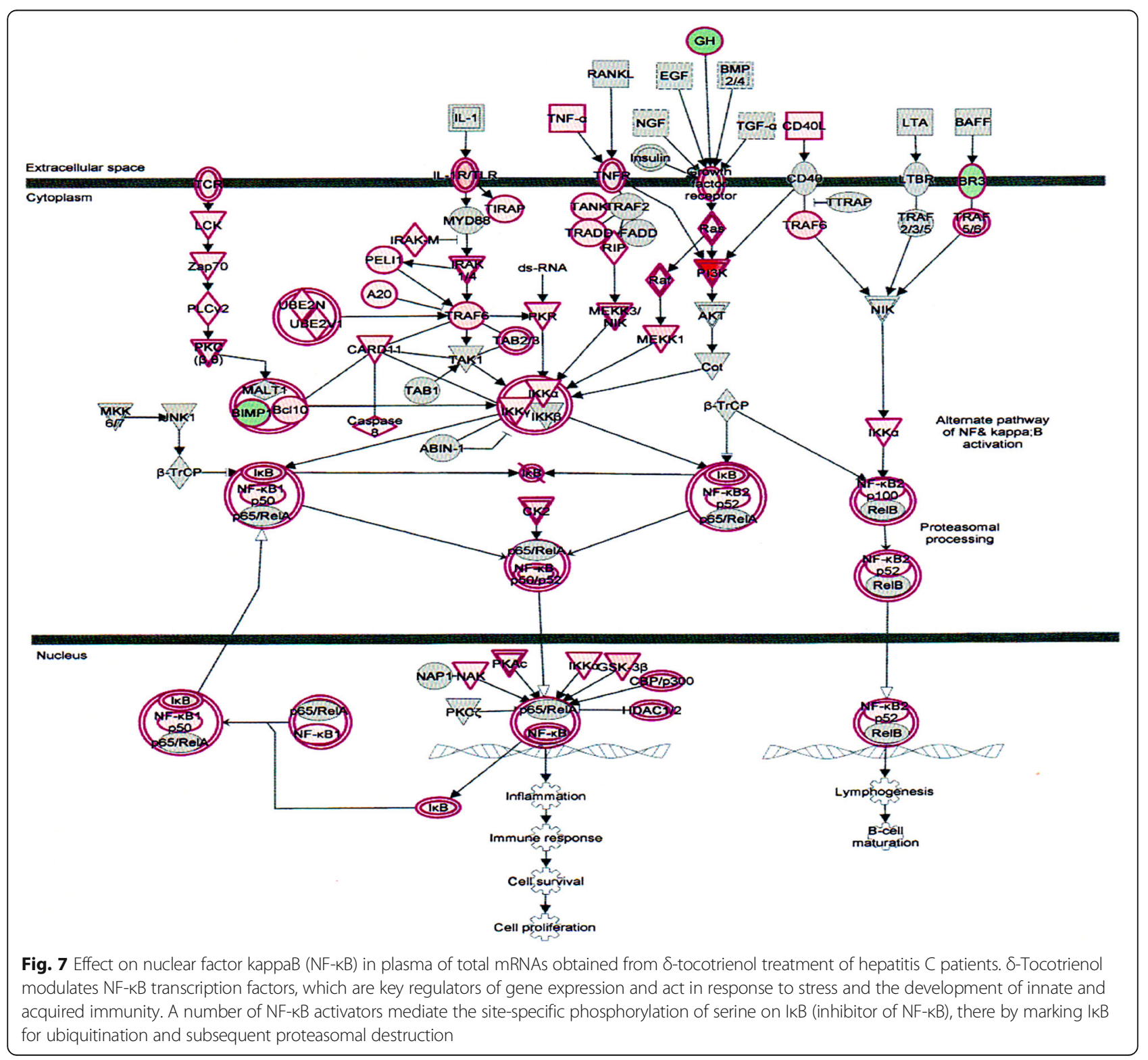


cell also activate nitric oxide production. IFN $\gamma$ activates JAK family kinases to trigger JAK/STAT signaling, leading to synthesis of the transcription factor IRF1 and stimulation of a large number of iNOS mRNA transcription [38]. The iNOS signaling pathways (Fig. 8) shows all possible regulators of production of nitric oxide, and highlights the important molecular events leads to production in macrophages. Collectively, IFN- $\gamma$ induced by $\delta$-tocotrienols would be expected to modulate the JAK/ STAT pathway and NO production.

Interleukin-6 (IL-6) is a regulator of acute phase responses and a lymphocyte stimulatory factor. The central role of IL-6 is for the management of infectious and inflammatory diseases [39]. IL-6 responses transmitted through glycoprotein 130 (GP130), which serves as the universal signal-transducing receptor subunit for all IL-6 related cytokines. Moreover,
IL-6-type cytokines utilize tyrosine kinases of the Janus kinase (JAK) family and signal transducer/activators of STAT transcription family as major mediators of signal transduction [40]. In addition to the JAK/STAT pathway of signal transduction, IL-6 also activates the extracellular signal-regulated kinases (ERK1/ 2) of the mitogen activated protein kinase (MAPK) pathway (Fig. 9). The upstream regulators of ERK1/2 include RAS and the src homology-2 containing proteins GRB2 and SHC. The SCH protein activate by JAK2 and thus serves as a link between the IL-6 activated JAK/STAT and RAS-MAPK pathways shown in IL-6 signaling pathway Fig. 9 [41]. Furthermore, phosphorylation of MAPKs in response to IL- 6 activated RAS results in the activation of nuclear factor IL-6 (NF-IL-6), which in turn stimulates the transcription of the IL- 6 gene. IL- 6 gene transcription is also stimulated by TNF- $\alpha$ and IL- 1 via activation of NF- $\mathrm{KB}$

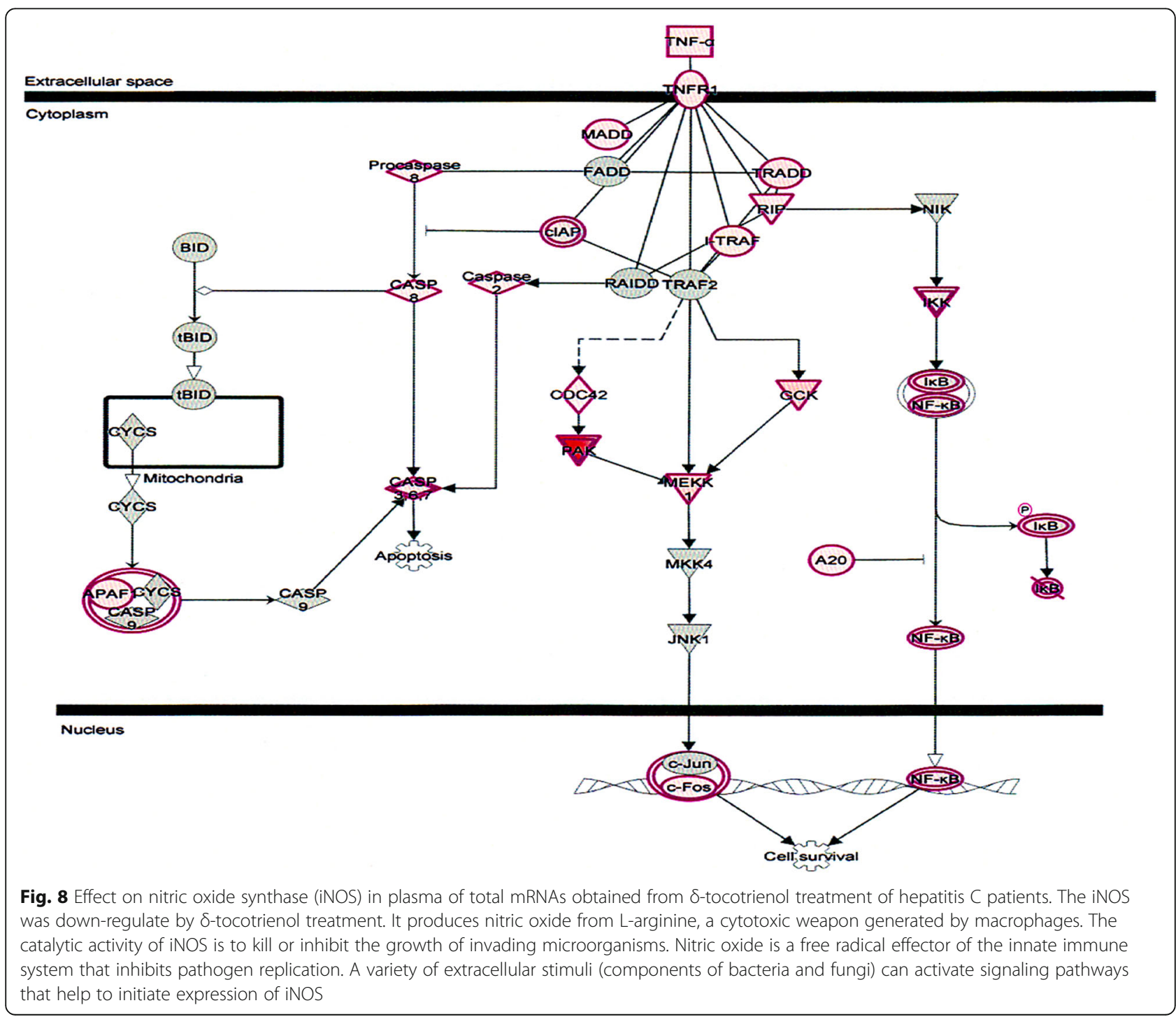


[41-43]. The tumor necrosis factor receptor (TNFR1) belongs to a family of 20 in mammalian cells.

TNF- $\alpha$, an important cytokine involves in cell proliferation, differentiation, and apoptosis modulate immune responses and induction of inflammation [44]. TNF- $\alpha$ functions through two receptors, TNFR1 TNFR2. TNFR1 is expressed in human tissue and TNFR2 expressed in immune cells (Fig. 10) [44, 45]. $\delta$-Tocotrienol also inhibits expression of IL-6 and TNFR induction in chronic hepatitis $\mathrm{C}$ patients.

Autophagy is a basic catabolic mechanism that involves cellular degradation of unnecessary or dysfunctional cellular components through the actions of liposome [46, 47]. Autophagy is generally activate by condition of nutrient deprivation but has also been associated with physiological as well as pathological processes such as development, differentiation, neurodegenerative diseases, stress, infection, and cancer [47-49]. The mammalian target of rapamycin (mTOR) kinase is a critical regulator of autophagy induction, with activated mTOR (AKT and MAPK signaling) suppressing autophagy, and negative regulation of mTOR
(AMPK and p53 signaling) promoting it [48]. The autophagy pathway (Fig. 11) highlights the key molecular events involved in triggering autophagy. Inhibiting the proteasome activity also causes the onset of autophagy, as observed with $\delta$-tocotrienol treatment.

Whereas, apoptosis is a coordinated energy-dependent process that involves the activation of a group of cysteine proteases called caspases and a cascade of events that link the initiating stimuli to programmed cell death [50]. The two main pathways of apoptosis are the intrinsic and extrinsic pathways. Each pathway requires specific triggers to initiate a cascade of molecular events that converge at the stage of caspase-3 activation [50]. The activation of caspase- 3 in turn triggers an execution pathway resulting in characteristic cytomorphological features including cell shrinkage, membrane blabbing, chromatin condensation and DNA fragmentation [51]. Further details of intrinsic and extrinsic pathways were found in the attached Ingenuity Apoptosis Signaling Pathway (Fig. 12), which highlights the key molecular events involved in trigging apoptosis.

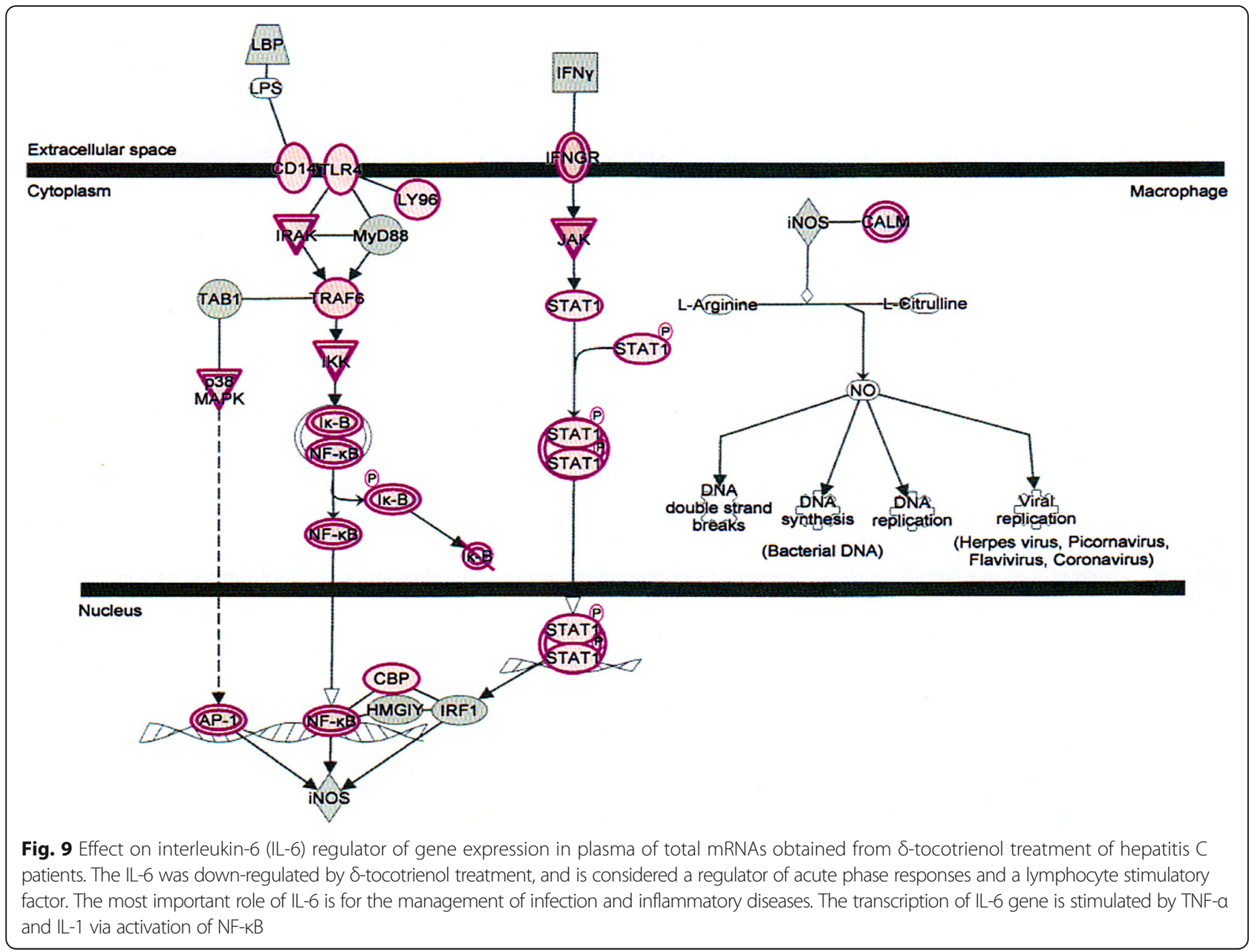




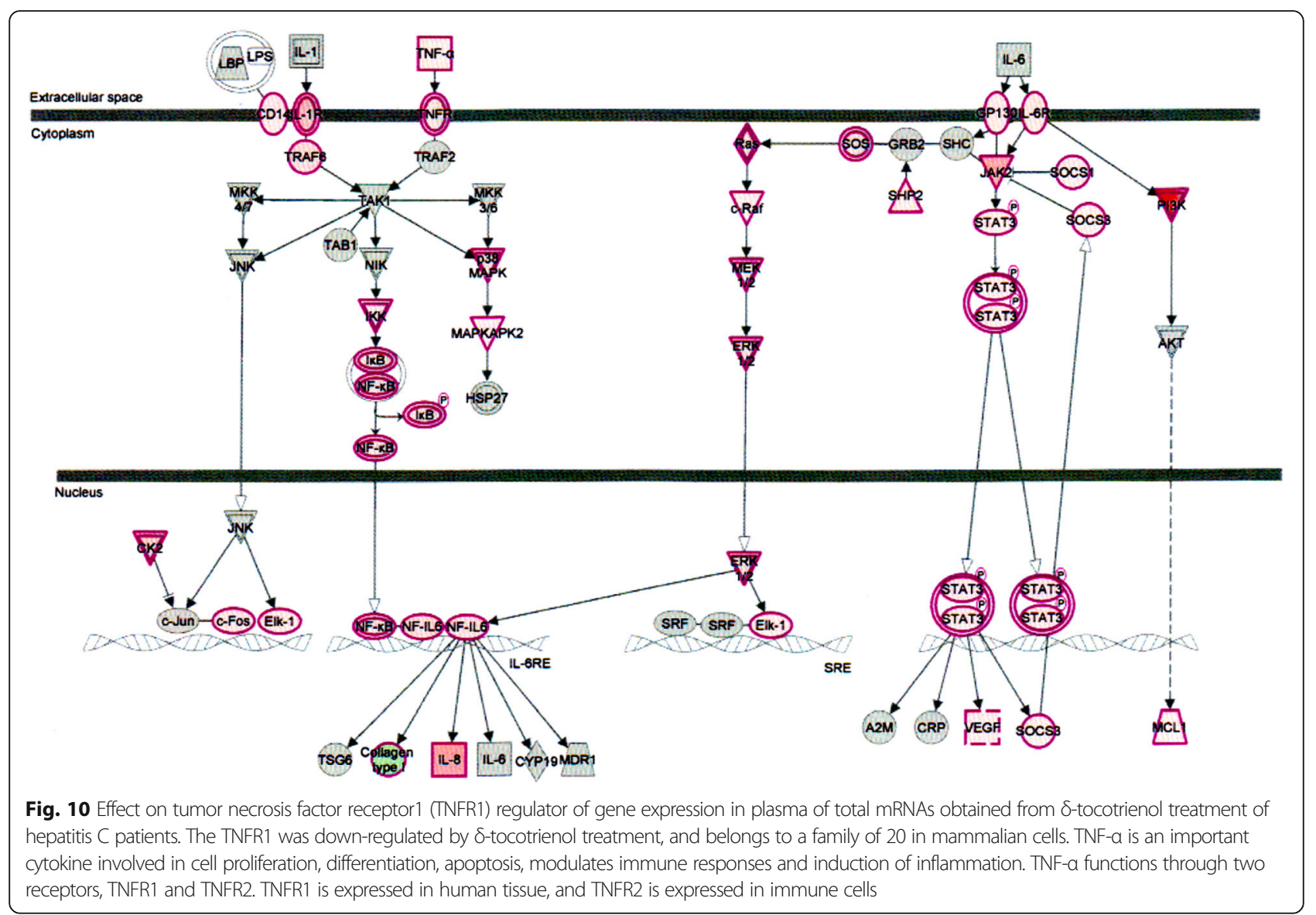

Beside these, other regulators were also affected by $\delta$-tocotrienol treatment of hepatitis $C$ patients, and they are interferon signaling, IL-2 signaling, and HMGB1 signaling, Cardiac hypertrophy signaling, Th1 and Th2 activation pathway, production of nitric oxide and reactive oxygen species in macrophages, Osteoarthritis pathway, PPAR signaling, type,I diabetes mellitus signaling, Type II diabetes mellitus, and insulin receptor signaling. In summary, EIF2 signaling regulator is at the top of the canonical pathway list but its fold change expression value is 221 as compared to protein ubiquitination pathway is 265 fold. On the other hand, osteoarthritis (210 fold), mammalian target of rapamycin (mTOR-201 fold), IL-8 (197 fold), Th1-Th2 (185 fold), PPAR $\alpha / R X R \alpha$ activation (180 fold), NF-KB (181 fold), IL-6 (128 fold), Type II diabetes mellitus signaling (128 fold), and nitric oxide signaling in cardiovascular system (113 fold), all have lower fold change expression compared to EIF2. This indicates the importance of $\delta$-tocotrienol on so many biological activities and signaling pathways (Table 11). The importance of most of these regulators was discussed in our several publications during course of the last decade $[1,11-15]$.

\section{Conclusions}

Present results of fold-change expression data analyzed by "Ingenuity Pathway Analysis" describe the effect of $\delta$-tocotrienol in chronic hepatitis $C$ patients on biological mechanisms at molecular level. It also revealed an insight of correlation of signaling pathways and transcriptional factors. Recently, two comprehensive reviews on the several biological activities of tocotrienols as hypocholesterolemic, anti-inflammatory, anticancer, antioxidant, neuroprotective, skin protection benefits, bone health and longevity have been published $[52,53]$. These articles also cover the beneficial properties of different isomers of tocotrienols treatment along with possible mechanisms, signaling pathways in breast, prostate, pancreas, rectal cancers in cell lines and humans $[52,53]$. Major signaling pathways that were affected by $\delta$-tocotrienol treatment in chronic hepatitis $\mathrm{C}$ subjects are summarized in the Table 12. The collective results indicate that tocotrienols inhibit cancer cell proliferation, promotes cell cycle arrest, decreases angiogenesis and acts via multiple signaling pathways [1]. Our present results are consistent with these conclusions and $\delta$-tocotrienol treatment of hepatitis $\mathrm{C}$ patients, acts by increasing cell death, and necrosis of 

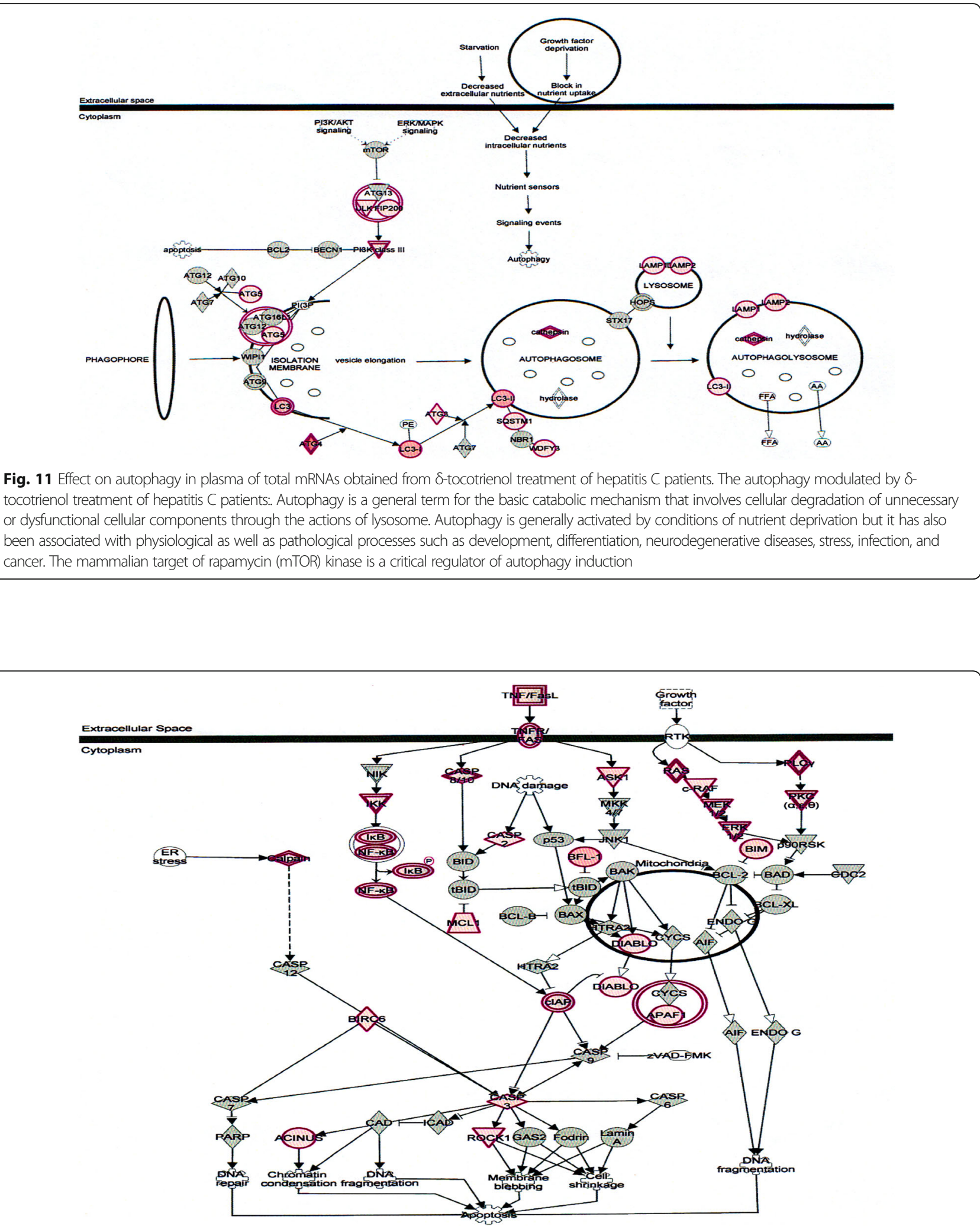

Fig. 12 Effect on apoptosis in plasma of total mRNAs obtained from $\delta$-tocotrienol treatment of hepatitis $C$ patients. Apoptosis modulated by $\delta$-tocotrienol treatment of hepatitis $C$ patients. Apoptosis is a coordinated energy-dependent process that involves the activation of a group of cysteine proteases called caspases and a cascade of events that link the initiating stimuli to programmed cell death. There are two main pathways of apoptosis, the intrinsic and extrinsic as shown here 
Table 12 Major signaling pathways affected by $\delta$-tocotrienol treatment in chronic hepatitis $C$ subjects

\begin{tabular}{ll}
\hline $\begin{array}{l}\text { Down-regulated by } \delta \text {-tocotrienol } \\
\text { treatment }\end{array}$ & $\begin{array}{l}\text { Up-regulated by } \delta \text {-tocotrienol } \\
\text { treatment }\end{array}$ \\
\hline $\begin{array}{l}\text { Proliferation of immune cells } \\
\text { Proliferation of mononuclear leukocytes }\end{array}$ & $\begin{array}{l}\text { Cell death and survival } \\
\text { Necrosis of malignant tumor } \\
\text { Viral infection }\end{array}$ \\
$\begin{array}{l}\text { Free radical scavenging } \\
\text { Endocrine system disorder, }\end{array}$ & Organismal Death \\
$\begin{array}{l}\text { Diabetes mellitus } \\
\text { Mobilization of Ca2+ }\end{array}$ & Cell death of cancer cells \\
Replication of virus & Cell death of tumors \\
HIV infection, replication of & \\
Influenza virus & \\
\hline
\end{tabular}

malignant tumors, and by decreasing viral infection, cellular growth and proliferation, decreasing endocrine system disorders such as diabetes mellitus, and mobilization of calcium. Therefore, tocotrienols can safely be used for hepatitis $C$ patients, without any side effects.

\section{Additional files}

Additional file 1: Table S1. Effect of d-tocotrienol on down-regulation of gene expression of "Molecules" (1-75) of IPA analyses in hepatitis C patients. (XLS $68 \mathrm{~kb}$ )

Additional file 2: Table S2. Effect of d-tocotrienol on down-regulation of gene expression of "Molecules" (76-150) of IPA analyses in hepatitis C patients. (XLS $68 \mathrm{~kb}$ )

Additional file 3: Table S3. Effect of d-tocotrienol on down-regulation of gene expression of "Molecules" (151-220) of IPA analyses in hepatitis C patients. (XLS $67 \mathrm{~kb})$

\section{Abbreviations}

EIF2: Eukaryotic translation initiation factors; ICAM1: Intercellular adhesion molecule1; IL-6: Interleukin-6; IPA: Ingenuity Pathway Analysis; mTOR: Mammalian target of rapamycin; NF-kB: Nuclear factor kappaB; TNF-a: Tumor necrosis factor-a; VCAM1: Vascular cell adhesion molecule1

\section{Acknowledgements}

We thank Ms. Suman Chaudhary as coordinator of collecting total mRNAs samples and estimation of quality control of total mRNAs for RNA-sequence analyses of various samples. The study was carried out under a FDA approved IND number 36906.

\section{Funding}

The study supported in part by Advanced Medical Research, Madison Wisconsin and NIH funds RO1 GM50870, 3RO1 GM631S1, and 5RO1 GM10263.

\section{Availability of data and materials}

All data generated or analyzed during this study are included in this article.

\section{Author's contributions}

AAQ and DAK conceived and planned the study to carry out RNA-sequence analysis after feeding $\delta$-tocotrienol to chronic hepatitis C patients; AAQ wrote the manuscript. DAK and SM carried out human study and prepared total mRNAs after feeding $\delta$-tocotrienol to chronic hepatitis C patients. SQY and
MX have carried out RNA-sequence analyses, including data analyses. NQ has edited the manuscript and also involves in data analyses of RNA-sequence. $N Q$, and DAK were also involved in proof reading of this manuscript. All authors have read and approved the final manuscript.

\section{Ethics approval and consent to participate}

The study carried out at the Pakistan Ordinance Factory (POF) Hospital, Wah Cantonment, Rawalpindi, 64,000, Pakistan, in collaboration with the Department of Basic Medical Sciences, University of Missouri-Kansas City, MO, USA. The study protocol registered (IRB \# 129-2015) and approved by Institutional Review Board of POF Hospital, Rawalpindi, 64,000, Pakistan.

All subjects signed an informed-consent form, which approved by Institutional Board of POF Hospital, Rawalpindi, 64,000 , Pakistan. The purified total RNA samples delivered at UMKC, School of Medicine after getting approval by the members "Compliance Officer (Christopher Winders)" and "Chemical Biological Safety Officer (Timothy Sturgis, RBP)" of Institution Board of UMKC School of Medicine, Kansas City, MO. USA.

\section{Consent for publication}

All contributing authors agree to the publication of this article.

\section{Competing interests}

The authors declare that they have no competing interests.

\section{Publisher's Note}

Springer Nature remains neutral with regard to jurisdictional claims in published maps and institutional affiliations.

\section{Author details}

${ }^{1}$ Department of Biomedical Science, School of Medicine, University of Missouri-Kansas City, 2411 Holmes Street, Kansas City, MO 64108, USA. ${ }^{2}$ Department of Chemical Pathology and Endocrinology, Armed Forces Institute of Pathology (AFIP), National University of Medical Sciences, Rawalpindi 64000, Pakistan. ${ }^{3}$ Division of Experimental and Translational Genetics, Department of Pediatrics, Childern's Mercy Hospital, 2401 Gillham Road, Kansas City, MO 64108, USA. ${ }^{4}$ Department of Biomedical and Health Informatics, School of Medicine, University of Missouri-Kansas City, 2411 Holmes Street, Kansas City, MO 64108, USA. ${ }^{5}$ Pharmacology/Toxicology, School of Pharmacy, University of Missouri-Kansas City, 2464 Charlotte Street, Kansas City, MO 64108, USA.

Received: 17 April 2018 Accepted: 26 June 2018

Published online: 21 July 2018

\section{References}

1. Qureshi AA, Eleanor Z, khan DA, Shahida M, Silswal N, Qureshi N. Proteasomes inhibitors modulate anticancer and anti-proliferative properties via NF-KB signaling, and ubiquitin-proteasome pathways in cancer cell lines of different organs. Lipids Health Dis. 2018;17:62. https://doi.org/10.1186/ s12944-018-0697-5.

2. Shepard CW, Finelli L, Alter MJ. Global epidemiology of hepatitis $C$ virus infection. Lancet Infect Dis. 2005;5(9):558-67.

3. Hamid S, Umar M, alam A, Siddiqui A, Qureshi H, Butt J. PSG consensus statement on management of hepatitis C virus infection-2003. J Pak Med Assoc. 2004;54(3):146-50.

4. DeRisi J, Penland L, Brown PO, Bittner ML, Meltzer PS, Ray M, Chen Y, Su YA, Trent JM. Use of a cDNA microarray to analyse patients in human cancer. Nat Genet. 1996;14(4):457-60.

5. Patil MA, Chua MS, Pan KH, Lin R, Leh, Cheung ST, Ho C, Li R, Fan ST, Cohen SN, Chen X, So S. An integrated data analysis approach to characterize genes highly expressed in hepatocellular carcinoma. Oncogene. 2005;24(23): $3737-47$.

6. Shackel NA, McGuinness PH, Abbott CA, Correll MD, McCaughan GW. Insight into the pathobiology of hepatitis $C$ virus associated cirrhosis: analysis of intrahepatic differential gene expression. Am J Pathol. 2002; 160(2):641-54.

7. Smith MW, Yue ZN, Korth MJ, Do HJ, Boix L, Fausto N, Bruix J, Carithers RL $J$ r, Katze MG. Hepatitis $C$ virus and liver disease: global transcriptional profiling and identification of potential markers. Hepatology (Baltomore, MD). 2003;38(6):1458-67. 
8. Zein NN. Clinical significance of hepatitis C virus genotypes. Clin Microbiol Rev. 2000;13(2):223-35.

9. Galardi S, Fatica A, Bachi A, Scaloni A, Presutti C, Bozzoni I. Purified box C/D snoRNAs are able to reproduce site-specific 2;-O-methylation of target RNA in vitro. Mol Cell Biol. 2002;22(19):6663-8.

10. Tycowski KT, Shu MD, Steitz JA. A small molecular RNA is processed from an intron of the human gene encoding ribosomal protein S3. Genes Dev. 1993; 7(7A):1176-90

11. Albig W, Kioschis P, Poustka A, Meergans K, Doeneck D. Human histone gene organization: nonregular arrangement within a large cluster. Genomics. 1997;40(2):314-22.

12. Zhang DD, Wang WT, Xiong J, Xie XM, Cui SS, Zhao ZG, Li MJ, Zhang ZQ, Hao DL, Zhao X, Li J, Wang J, Chen HZ, Lv X, Liu DP. Long noncoding RNA LINC00305 promotes inflammation by activating the AHRR-NF-KB pathway in human monocytes. Sci Rep. 2017:10(7):46204. https://doi.org/10.1038/ srep46204.

13. Doyard M, Fatih N, Monnier A, Island ML, Aubry M, Leroyen P, Bouvet R, Charles G, Loreal O, Guggenbuhl P. Iron excess limits HHIPL-2 gene expression and decreases osteoblastic activity in human MG-63 cells. Osteoporos Int. 2012;10:2435-45. https://doi.org/10.1007/s00198-011-1871-z. PMID 22237814

14. Strichman-Almashanu L, Bustin M, Landsman D. Retroposed copies of the HMG genes: a window to genome dynamics. Genome Res. 2003;13:800-12.

15. Rogalla P, Botda Z, Meyer-Bolte K, Tran KH, Hauke S, Nimzyk R, Bullerdiek J. Mapping and molecular characterization of five HMG1-related DNA sequences. Cytogen Cell Genet. 1998;83:124-9.

16. Kiss T. Small nuclear RNAs: an abundant group of noncoding RNAs with diverse cellular functions. Cell. 2002;109(2):145-8

17. Stove EH, Konstantinopoulos PA, Matulonis UA, Swisher EM. Biomarkers of response and resistance to DNA repair targeted therapies. Clin Cancer Res. 2016;22(23):5651-60

18. Arno G, Carss K, Hull S, Zihni C, Robson AG, Fiorentino A, UK Inherited Retinal Disease Consortium, Hardcastle AJ, Holder GE, Cheetham ME, Plagnol V, NIHR Bioresource-Rare Disease Consortium, Moore AT, Raymond FL, Matter K, Balda MS, Webster AR. Biallelic mutation of ARHGEF18, involved in the determination of epithelial apicobasal polarity, causes adultonset retinal degeration. Am J Hum Genet. 2017;100(2):334-42.

19. Houchins JP, Yabe T, McSherry C, Bach FH. DNA sequence analyses of NKG2, a family of related cDNA clones encoding type II integral membrane proteins on human natural killer cells. J Exp Med. 1991;173:1017-20.

20. Albig W, Doenecke D. The human histone gene cluster at the D6S105 locus, Human Genet. 1997:101(3):284-94.

21. Marzluff WF, Gongidi P, Woods KR, Jin J, Maltais L. The human and mouse replication-dependent histone genes. Genomics. 2002;80(5):487-98.

22. Dayan A, Bertrand R, Beachemin M, Chahla D, Mamo A, Filion M, Skup D, Massie B, Jolivet J. Cloning and characterization of the human 5,10methenyltetrahdrofolate synthase-encoding cDNA. J Gene. 1995;165(2): $307-11$

23. Bertrand R, Beauchemin M, Dayan A, Quimet M, Jolivet J. Identification and characterization of human mitochondrial methenyltetrahdrofolate synthetase activity. Biochem Biophys Acta. 1995;1266:245-9.

24. Murry JL, Sheng J, Rubin DH. A role for H/ACA and C/D small nucleolar RNAs in viral replication. Mol Biotechnol. 2014:56:429-37.

25. Zhang D, Zhang G, Hayden MS, Greenbaltt MB, Bussey C, Flavell RA, Ghosh $\mathrm{S}$. A toll-like receptor that prevents infection by urophathogenic bacteria. Science. 2004;303:1522-6.

26. Kien E, Means TK, Heine $\mathrm{H}$, et al. Toll-like receptor 4 imparts lagand-specific recognition of bacterial lipopolysaccharide. J Clin Invest. 2000;105:497-504.

27. Silva CM. Role of STATs as downstream signal transducers in Src family kinase-mediated tumorigenesis. Oncogene. 2004;23(48):8017-23.

28. Lin CP, Cao X. Structure, function, and regulation of STAT protein. Mol BioSyst. 2006;2(11):536-50.

29. Yuan ZL, Guan YJ, Wei W, Wang L, Kane AB, Chin YE. Central role of the threonine residue within the $\mathrm{p}+1$ loop of trceptor tyrosine kinase in STAT3 constitutive phosphorylation in metastatic cancer cells. Mol Cell Biol. 2004; 24(21):9390-400

30. Karin $\mathrm{M}$. The beginning of the end: IKB kinase (IKK) and NF-KB activation. J Bol Chem. 1999;274:27339-42.

31. Palombella VJ, Rando OJ, Goldberg AL, Maniatis T. The ubiquitinproteasome pathway is required for processing the NF-KB precursor protein and activation of NF-kB. Cell. 1994;78:773-85.
32. Moncada S, Higgs A. The L-arginine-nitric oxide pathway. N Engl J Med. 1993:329:2002-12

33. Moncada S, Palmer RM, Higgs EA. Nitric oxide: physiology, pathophysiology and pharmacology. Pharmacol Rev. 1991;43:109-42.

34. Forstemann U, Closs El, Pollock JS, Nakane M, Schwarz P, Gath I, Kleinert H. Nitric oxide synthase isozyme: characterization, purification, molecular cloning and functions. Hypertension. 1994;23(pt 2):1121-31.

35. Nadaud S, Sobrier F. Molecular biology and molecular genetics of nitric oxide synthase genes. Clin Exp Hypertens. 1996;18:113-43.

36. Nathan C, Xie O. Nitric oxide synthase: roles, tolls and controls. Cell. 1994;78: 915-8.

37. Qureshi N, Vogel SN, Van Way C III, Papasian CJ, Qureshi AA, Morrison DC. The proteasome. A central regulator of inflammation and macrophage function. Immunol Res. 2005;31(3):243-60.

38. Ma C, Wang DL, Li M, Cai W. Anti-inflammatory effect of resveratrol through the suppression of NF-kB and JAK/STAT signaling pathway. Acta Biochim Biophys Sin. 2015;17(3):207-13.

39. Kallen KJ, zum Buschenfelde KH, Rose-John S. The therapeutic potential of interleukin-6 hyperagonists and antagonists. Expert Opin Investig Drugs. 1997:6(3):237-66.

40. Heinrich PC, Behrmann I, Muller-newen G, Schaper F, Graeve F. Interleukin6-type cytokine signaling through the gp 130/Jak/STAT pathway. Biochem J. 1998;334(pt 2):297-314.

41. Brandt C, Pedersen BK. The role of exercise-induced myokines in muscle homeostasis and the defense against chronic diseases. J Biomed Biotechnol 2010; Article ID 520258, 6 pages. Doi:https://doi.org/10.1155/2010/520258.

42. Munoz-Canoves P, Scheele C, Pedersen BK, Serrano AL. Interkin-6 myokine signaling in skeletal muscle: a double-edged sword? FEBS J. 2013;280(17): $4131-48$

43. Meador BM, Krzyszton CP, Johnson RW, Huey KA. Effects of IL-10, and age on IL-6, IL-1b, and TNF-a responses in mouse skeletal and cardiac muscle to an acute inflammatory insult. J Appl Physiol. 2008;104:991-7.

44. Beutler B, Greenwald D, Hulmes JD, Chan M, Pan YC, Matuison J, Ulevith R, Cerami A. Identity of tumor necrosis factor and macrophage-secreted factor cachectin. Nature. 1985:316(6028):552-4.

45. Soranzo C, Perego P, Zunino F. Effect of tumor necrosis factor on human tumor cell lines sensitive and resistant to cytotoxic drugs, and its interaction with chemotherapeutic agents. Anti-Cancer Drugs. 1990;1 (2):157-63.

46. Ziparo E, Petrungaro S, Marini ES, Starace D, Conti S, Facchiano A, Filippini A, Giampietri C. Autophagy in prostate cancer and androgen suppressioin therapy. Int J Mol Sci. 2013;12:12090-106. https://doi.org/10.3390/ ijms140612090. (ISSN 1422-0067)

47. Rubinsztein $D C$, Bento $C F$, Deretic V. Therapeutic targeting of autophagy in neurodegenerative and infectious diseases. J Exp Med. 2015;212(7):979-90.

48. Nedelsky NB, Todd PK, Taylor JP. Autophagy and ubiquitin-proteasome system: collaborators in neuroprotection. Biochim Biophys Acta. 2008;1782: 691-9.

49. Zhu K, Dunner K Jr, McConkey DJ. Proteasome inhibitors activate autophagy as a cytoprotective response in human prostate cancer cells. Oncogene. 2010:29:451-62.

50. King LB, Ashwell JD. Thymocyte and T cell apoptosis: is all death created equal? Thymus. 1994-1995;23(3-4):209-30.

51. Zhang N, Hartig H, Dzhagalov I, Draper D, He YW. The role of apoptosis in the development and function of T lymphocytes. Cell Res. 2005;15(10):749-69.

52. Kanchi MM, Shanmugan MK, Rane G, Sethi G, Kumar AP. Tocotrienols: the unsaturated sidekick shifting new paradigms in vitamin E therapeutics. Drug Discov Today. 2017;22(12):1765-81.

53. Sailo BL, Banik K, Padmavathi G, Javadi M, Bordoloi D, Kunnumakkara AB. Tocotrienols: the promising analogue of vitamin $\mathrm{E}$ for cancer therapeutics. Pharmacol Res. 2018;130:259-72.

54. Qureshi AA, Khan DA, Mahjabeen W, Trias AM, Silswal N, Qureshi N. Impact of $\delta$-tocotrienol on inflammatory biomarkers and oxidative stress in hypercholesterolemic subjects. J Clin Exp Cardiolog. 2015;6:4. https://doi. org/10.4172/2155-9880.1000367. 